\title{
Issue Attention on International Courts: Evidence from the European Court of Justice
}

\author{
Arthur Dyevre* and Nicolas Lampach ${ }^{\dagger}$
}

January 22, 2020

\begin{abstract}
We exploit variations in access rules on the European Court of Justice to explore the effect of procedural inclusiveness on the agenda of international adjudicators. Using natural language processing methods, we analyse the entire universe of ECJ decisions up to 2015, mapping issue prevalence across time, procedures and litigant type. We find evidence that the more inclusive annulment and referral procedures are associated with greater issue heterogeneity whereas less inclusive infringement procedure displays greater issue cohesiveness as well as greater issue stability over time.
\end{abstract}

Keywords: International courts; Judicial agenda; Litigation; Text-mining; Topic model JEL Classification: C38, C46, J68, K19

Acknowledgment The authors gratefully acknowledge financial support from European Research Council Starting Grant 638154 (EUTHORITY). We are grateful to Monika Glavina, Russell Neudorf and Anna Maria Tonikidou for invaluable research assistance.

* Corresponding author: KU Leuven Faculty of Law, Centre for Legal Theory and Empirical Jurisprudence, 45 Tiensestraat, Leuven, Belgium; E-mail: arthur.dyevre@law.kuleuven. be; Phone: +3216325387

$\dagger$, KU Leuven Faculty of Law, Centre for Legal Theory and Empirical Jurisprudence; E-mail: nicolas. lampach@kuleuven. be 


\section{Introduction}

Understanding how a policy-making institution sets its agenda is crucial to understanding what and how it makes policies. This should hold for courts as well as for legislatures and other public institutions. Judicial agenda-setting, though, looks a comparatively understudied topic, at least outside the institutional context peculiar to the US Supreme Court (Perry, 2009; Kastellec and Lax, 2008). This neglect may in part be explained by the common assumption that courts cannot act ex officio. That is, in order to make policy pronouncements, courts must wait for a litigant to file a suit. If no litigant is able or willing to do so, the courts will be kept out of the issue. So, since judges have seemingly little or no control over their agenda, judicial agenda-setting seems a pointless research question, except perhaps in the rare instances where, as do the justices on the US Supreme Court, they enjoy full docket discretion. ${ }^{1}$ To political scientists more accustomed to use the term "agenda-setting" or "agenda formation" in the legislative or media context, the notion of "judicial agenda-setting" may seem to lack intuitive clarity. Another reason for the apparent lack of scholarly interest in judicial agenda formation stems from the methodological challenge involved in analysing large amounts of textual information. It is not untypical for a court to decide hundreds, sometimes thousands, of cases every year. Moreover, the issues courts get to decide are articulated in complex, unstructured opinions that easily span dozens of pages. Manually curating the relevant information from such a mass of documents, therefore, is a task beyond the resources of most research projects. The general scholarly neglects extends to international courts, although scholars generally agree that access rules constitute an important parameter of the power of international adjudicators (Keohane et al., 2000; Alter, 2006, 2001, 2012; Conant, 2006).

In this paper we conceptualise judicial agenda-setting as a function of the interplay of judges and case initiators within the constraints of the applying access rules, notably the rules governing standing. We explore how variations in these access rules affect the agenda of a prominent international adjudicatory body, the European Court of Justice (ECJ). The trajectory of legal integration in Europe along with the ECJ's institutional architecture make the Court's rulings a particularly interesting case to investigate the relationship between access rules and judicial agenda-setting. While European integration has been accompanied by a rapid expansion of the policy remit of EU institutions, the impact of this evolution on litigation and the ECJ's agenda has been mediated by a highly differentiated procedural setup. Access to the ECJ is governed by separate procedures, which

\footnotetext{
${ }^{1}$ For a discussion of case selection on the US Supreme Court see Perry (2009), Caldeira et al. (1999) and Kastellec and Lax (2008).
} 
contemplate different objects and empower distinct sets of litigants. The ECJ context offers the rare possibility to compare the effect of procedural variation within the same international organization, which automatically controls for a host of important factors - including the composition of the Court, the membership of the organization and the legal basis - that could otherwise confound the analysis (Gabel et al., 2012, 1126). We argue that more inclusive procedures like the preliminary ruling mechanism and the annulment procedure enable international adjudicators to mobilise a broader and more diverse pool of litigants. Because they limit the ability of judges to engage and mobilise new litigants, less inclusive procedures such as the infringement procedure - which restrict the right to bring cases to a supranational body or to member state governments - make a court's agenda less dynamic but more cohesive and stable over time. In consequence, we contend that preliminary rulings and annulment decisions should be expected to display greater issue diversity and greater agenda shifts over time than infringement cases. We collect the entire universe of ECJ rulings up to 2015 and use various topic models along with corpus dissimilarity analysis to measure, visualize and compare issue prevalence across time, procedures and litigant characteristics. We find evidence that the more inclusive procedures are associated with greater issue diversity whereas the less inclusive infringement procedure is associated with both greater issue stability and greater issue cohesiveness. Infringement cases tend to focus on internal market and environmental issues, reflecting the European Commission's enforcement priorities. Preliminary rulings address a broader range of topics, from customs and consumer protection to public procurement, employment, welfare benefits, driving licences and immigration. Annulment cases feature a medley of economic and administrative issues, including competition, trademark, agriculture, EU external relations and EU staff disputes. Annulment cases filed by national governments mostly relate to the agricultural guarantee fund, state subsidies to domestic industries, border crossing and food imports. Private litigants use the annulment procedure to challenge EU regulatory decisions on competition, dumping and trademarks, while cases brought by EU institutions tend to centre on external relations, environmental measures and competition issues. While some international courts established in Africa and Latin America have been modelled after the ECJ(Alter, 2012), we contend that our findings may also help shed light on agenda formation on other international courts where access rules are either inclusive or non-inclusive.

The paper proceeds as follows. Section 2 presents our theoretical framework and hypotheses. Section 3 explains our text-mining approach and Section 4 reports the results. We conclude with a brief discussion of the implications of our findings for other international courts. 


\section{Judicial Agenda Formation: Theory}

The US literature has considered how federal courts can create or suppress issues sua sponte (Epstein et al., 1996) and incentivise specific subsets of litigants to orient litigation in the direction judges deem most desirable (Baird, 2004; Baird and Jacobi, 2009). International courts, however, differ significantly from US federal courts, particularly with regard to the rules governing their access. Students of international international courts tend to associate private actor access with greater judicial influence and effectiveness (Keohane et al., 2000; Alter, 2006, 2001, 2012; Conant, 2006). Yet this literature has not worked out systematically how variations in access rules affect judicial agenda formation.

\subsection{Standing, Docket Control and Issue Attention}

In democratic regimes, the rule is that legislatures freely set their agenda. ${ }^{2}$ Not only can legislators decide what and when to decide. They can also decide not to decide. In sum, legislators enjoy positive agenda control - the ability to get an issue onto the legislative agenda - as well as negative agenda control - the ability to keep issues off the legislative agenda. On the face of things at least, judicial institutions appear far more constrained in regard to both positive and negative agenda control. First, courts are normally dependent on the initiative of other actors. Unless a litigant brings issue A to the courts, the courts will not address issue $\mathrm{A}^{3}$ Second, if a litigant brings $\mathrm{A}$, the courts may have the obligation to address it, even in instances where they would deem it preferable to evade or delay A's resolution.

Judicial agenda formation, as we understand it, is determined by the interplay of litigants and judges within the institutional framework established by the applying access rules. These access rules encompass both the rules governing standing and those governing docket management. Docket management rules determine the judges' ability to remove cases from their docket. A mandatory docket means that judges must review all the cases that been filed. A discretionary docket means they are free to select only the ones they deem worth reviewing. Standing rules establish both who is entitled to lodge a suit and what

\footnotetext{
${ }^{2}$ This rule knows, of course, a number of exceptions. In parliamentary systems, legislative procedures may afford the executive branch substantive control over the agenda of the legislature (Huber, 1992). In the EU, the treaties severely restrict the agenda-setting powers of the European Parliament, the democratic world's largest supranational assembly.

${ }^{3}$ That policy questions are raised within the context of dispute resolution severely restricts the scope for issue creation. This is because policy determinations are expected to bear some relevance to the dispute being resolved (Cameron and Kornhauser, 2013). Judges cannot easily escape this institutional constraint.
} 
constitutes an admissible cause of action. Admissible causes of action may embrace challenges to the legality of executive or legislative acts, personal harm or criminal enforcement, while authorised case initiators may include individuals, private organisations, other courts and, under international regimes, sovereign states (Alter, 2006). Many combinations of standing and docket management rules are possible and the spectrum of institutional variation is large. Standing can extend to virtually all persons and organizations justifying a broadly defined cause of action. ${ }^{4}$ But it can be restricted to state parties or granted only on a very narrow set of grounds. To give some examples, only national governments can bring disputes before the International Court of Justice. The same holds for the WTO Dispute Settlement Body. Some international regimes allow individuals to file their claims with a commission, which then decides what cases to pass on to the international tribunal. The Inter-American Court of Human Rights and the European Court of Human Rights prior to 1998 illustrate such an arrangement. Other regimes have different standing rules depending on the cause of action and remedy. Intuitively, it is easy to see that where restrictive rules of standing combine with a mandatory docket, the exclusive circle of litigants enjoying standing may be in position to exert tight control over the judicial agenda. But where standing rules are more generous judges and docket management rules looser judges may have greater influence over litigation dynamics and, thereby, over the range of issues that land on their docket. The combination of broad rules of standing with a discretionary docket arguably afford US Supreme Court judges wide-ranging positive and negative agenda-setting powers, to the point of making them comparable to those of a legislature.

By determining how inclusive access to the court is, standing rules affect positive agenda control. Consider public (prosecutors, parliamentary groups, cabinet, ombudsman, etc.) and private (citizens, NGOs, corporations, etc.) litigants. They are likely to differ in their interests and motives for litigation but also in their number. In international legal regimes where only state parties can bring cases, for example, the pool of authorised litigants will never exceed the number of member states. Where, as with abstract review cases on constitutional courts, only parliamentary groupings have standing to initiate proceedings, the pool of potential litigants will be even smaller. Allowing for private actor access, on the other hand, may increase the number of potential litigants by several orders of magnitude. Besides being more numerous, private litigants also tend to be more

\footnotetext{
${ }^{4}$ The actio popularis, which allows any person to bring action in the interest of the public, can be viewed as an extreme variant of such an institutional arrangement. Such a procedure existed in Hungary between 1990 and 2011 before the Constitutional Court. The Hungarian actio popularis led to an explosion in constitutional litigation and allowed the Hungarian Constitutional Court to become one of the world's most activist judicial constitutional tribunals during this period (see Scheppele, 2005).
} 
heterogeneous. Corporations, NGOs and minorities, just rich and poor individuals have distinct, non-overlapping interests and are, therefore, unlikely to be driven by the same motives. Moreover, societal and legislative changes that impact these groups asymmetrically are likely to have an equally asymmetric impact on their incentives to litigate.

In their work on US courts, Jacobi (2008) and Baird and Jacobi (2009) suggest how courts can gain greater control over their agenda by signalling what issues they want to review to potential litigators. This presupposes, though, that standing rules are inclusive and guarantee access to private litigators. When this is the case, courts have the ability to socialize new litigants in the judicial process, who in turn will bring new issues to the courts. Where rules regarding locus standi are less inclusive, by contrast, courts cannot use this strategy to attract new litigants and expand the remit of their jurisprudence. Accordingly, we should generally expect more inclusive access rules to be associated with greater issue diversity and greater issue variability over time. With regard to international courts, this means we should expect greater issue heterogeneity when private actors are guaranteed access but greater issue cohesiveness and issue stability when access rules are more restrictive.

\subsection{ECJ: Procedural Differentiation and Litigation Dynam- ics}

The ECJ offers an interesting context to study the effect of variations in access rules on issue attention. Indeed, there are three distinct procedural channels to bring cases before the Court, each with its own standing rules. Yet the fact these variations exist within the same international adjudicatory body controls for a host of important factors that could otherwise confound the analysis. These factors include the composition of the Court, the membership of the organization and the legal basis. So we can safely assume that these factors are constant and keep our focus on the procedural variation (Gabel et al., 2012, 1126).

The ECJ operates under a mandatory docket regime. This is true for preliminary references as well as for annulment and infringement proceedings. In consequence, the Court's negative agenda control is very restricted and constant across procedure. ${ }^{5}$ Standing rules, by contrast, differ considerably across the three procedures. Not only do the causes of action differ, but also the classes of empowered litigants. First, the preliminary ruling mechanism established by

\footnotetext{
${ }^{5}$ The ability to dismiss cases that are "manifestly inadmissible" or references that pertain to "settled case law" affords the ECJ a limited measure of negative agenda control (Craig and Burca, 2015, 484). There has been no empirical research of note on issue suppression on the ECJ. We point it out as an interesting area for future research.
} 
Article 267 of the Treaty on the Functioning of the European Union (TFEU) permits national judges to refer questions to the ECJ regarding the application and interpretation of EU law. Formally, domestic judges are the gatekeepers of the procedure. Yet, because private litigants have the opportunity to try and persuade domestic judges to submit references, this channel is commonly viewed as giving private actors semi-direct access to the ECJ (Börzel, 2006; Alter, 2006; Keohane et al., 2000). The second access channel to the European Court is the infringement procedure laid down in Article 258 and 259 TFEU. The object of an infringement action is always the conduct of a member state alleged to have contravened EU law. The power to initiate infringement proceedings lies with the European Commission, which Article 258 elevates to the status of chief EU prosecutor. By virtue of Article 259 TFEU each member state is also formally vested with the right to initiate infringement proceedings against another member state. Private persons have the possibility to file complaints over breaches of EU law with the Commission - a practice encouraged by the Commission, which uses private complaints as a tool to detect violations (Harlow and Rawlings, 2006; Smith, 2008). However, the decision to bring a case before the Court is one over which the Commission always has the ultimate say. Finally, a case can reach the Court via the annulment procedure (Article $263 \mathrm{TFEU}$ ) when the object of the case is the abrogation of an EU act. Member states, the European Parliament, the European Commission or the Council have standing to bring annulment against any EU act. The Court of Auditors, the European Central Bank and the Committee of the Regions can also bring actions for the purpose of protecting their prerogatives. Private litigants and EU civil servants enjoy limited standing under this procedure. According to the ECJ's reading of Article 263 TFEU, private plaintiffs are entitled to bring annulment proceedings only when "directly" and "individually" affected by the EU measure at issue (Craig and Burca, 2015, 515). This precludes challenges to general EU legislative acts such as EU directives, but covers individual decisions as well as appeals against decisions of the General Court - the lower EU court.

Aside from empowering different classes of litigants, the three procedures just sketched out correspond to different judicial roles (Alter, 2006). In terms of their respective object, or cause of action, they overlap to some degree but not completely. EU acts can be challenged under both the annulment and preliminary ruling procedure, but not under the infringement procedure. Likewise, national legislation and practices can be challenged under both the infringement and preliminary ruling procedure, but not under the annulment procedure. Thus cross-procedural variations in relative issue prevalence can arise from differences in case initiators as well as from differences in permissible causes of action.

Generally speaking, because of their greater inclusiveness, we should expect the preliminary ruling procedure and, to a lesser extent, the annulment procedure 
to be associated with greater issue diversity. By contrast, we should expect the less inclusive infringement procedure to exhibit greater issue cohesiveness as well as greater issue stability over time. The preliminary ruling mechanism enables the ECJ to use its case law to socialize new domestic judges and litigants into the development of EU law (Jacobi, 2008; Baird and Jacobi, 2009). Similarly, changes to EU treaties and regulations may motivate new actors to push EU legislation. The annulment procedure allows for similar dynamics. But not the infringement procedure. The institutional configuration of the infringement procedure, together with the member states' reluctance to use Article 259, gives the European Commission's tight control over the issues that might seek their way to the Court's docket via this channel. As with EU legislative politics in general, the Commission's preferences and priorities characterised by ideological continuity and incremental change rather than abrupt U-turns (Hix, 2011). For that reason, we should expect issue attention in infringement rulings to closely mirror the Commission's policy agenda, notably its internal market agenda (Tallberg, 1999; Börzel, 2003), and to display greater stability and cohesiveness.

\section{Methodology: Automated Text Analysis}

The present Section introduces the natural language processing techniques we employ to investigate issue prevalence on the European Court of Justice. EU scholars, whether they are interested in path-dependency and policy spill-overs in EU law litigation (Schmidt, 2012; Sweet and Brunell, 1998; Stone Sweet, 2004) or clustering effects in referral activity (Kelemen and Pavone, 2016) often turn to case annotations from the official case report and "subject matter" categories from the Court of Justice's official database, CURIA, for information on issue attention. Three considerations motivate our choice to opt for a computerised text-mining approach over these manual case annotations. The first is the flexibility of text-mining techniques, especially topic modelling. Topic modelling allows the researcher to choose the degree of data reduction by setting the number of topics and facilitates the grouping of individual issues into broader themes. Second, unlike the said manual case annotations, which only provide a binary measure of the presence of a topic, text-mining methods offers a quantitative, document-level measure of issue proportion. Third, in contrast to the measure of issue attention supplied by the official case reports, our computerised approach is fully replicable. There is no documentation on the ECJ's internal case annotation process. In fact, it has been suggested that it does obey any systematic procedure. $^{6}$

\footnotetext{
${ }^{6}$ The coding protocol for the Court of Justice Cases dataset compiled by Clifford Carrubba advises against using issue area codes from the ECJ case books and refers to correspondence
} 
Rather than treating all the rulings as a single corpus, our approach treats each procedure as forming a distinct corpus of judicial texts. We construct separate topic models for each corpus and use corpus dissimilarity analysis to compare issue prevalence between corpora.

Before explaining how we apply these techniques to ECJ opinions, it is useful to say a few words about the type of research questions which they allow one to answer. Topic modelling and corpus dissimilarity analysis are descriptive, data-reduction methods. In that sense, they can be compared to item-response modelling, which is not used for causal inference but to construct sophisticated summaries of complex patterns, such as roll-call or judicial votes (Martin and Quinn, 2002; Hix et al., 2009; Voeten, 2007). There too lie some of the limitations of these methods. Our computer-based approach is able to map patterns of issue attention across the three procedures in great detail. Yet, although they allow us to determine whether there is a link between issue prevalence and variations in access rules, we cannot identity or test the exact causal mechanism at work.

\subsection{Probabilistic Topic Modelling}

Probabilistic topic modelling is a suite of methods developed for the purpose of discovering and annotating large archives of documents with thematic information (Blei, 2012). The simplest topic modelling technique is based on latent Dirichlet allocation (LDA). The basic intuition behind LDA is that documents addressing the same topic are likely to contain similar words. Words such as "import", "products" and "trade" will appear more often in decisions about barriers to cross-border trade whereas "milk", "quantity" and "amounts" will be more common in decisions about farming regulations. A judicial decision will typically concern more than one topic (Shapiro, 2008; Edelman and Chen, 2007). A decision about trade may also raise procedural questions or a case may pertain to the importation of dairy products. LDA builds on these assumptions to model topics as a cluster of words and documents as a mixture of topics. More specifically, it posits a latent space in which topics are represented as distributions over words and documents as distributions over topics (Chang et al., 2009; Blei, 2012; Blei et al., 2003). The number of topics $K$ is set by the researcher-although heuristics, such as perplexity and semantic exclusivity, have been proposed (Wallach et al., 2009; Chang et al., 2009; Mimno et al., 2011). The $K$ parameter determines how fine-grained a summary of the corpus the final topic model will provide. Varying the number of topics thus effectively allows the analyst to zoom in and out to find specific or broader themes. As opposed to the number of topics, the words

with the Court as indication that the choice of terms is not based on a well-defined coding scheme from the Court. See http://polisci.emory.edu/home/people/carrubba_ecjd/ECJ_ Access_Data_Codebook.pdf (Accessed 5 July 2018). 
defining the topics are not chosen by the researcher but emerge from the analysis of the documents. To find the topics and assign the documents to the topics, LDA effectively treats the observed data, the word counts in the documents, as arising from a hidden generative process. The goal of the estimation is to infer this hidden topic structure from the observed documents.

The proportion of topics in documents is treated as a random variable drawn from a Dirichlet prior distribution. Formally, estimating an LDA model requires computing the following posterior distribution:

$$
p\left(\beta_{1: K}, \theta_{1: D}, z_{1: D}, w_{1: D}\right)=\frac{p\left(\beta_{1: K}, \theta_{1: D}, z_{1: D} \mid w_{1: D}\right)}{p\left(w_{1: D}\right)} .
$$

where $\beta_{1: K}$ are the topics and $\beta_{k}$ is the distribution over words for topic $k ; \theta_{d}$ is the topic proportion for document $d$ (and $\theta_{d, k}$ is the proportion of topic $k$ in document $d) ; z_{d}$ is the topic assignments for words in document $d$ and $w_{d}$ are the observed words for document $d$. The numerator on the right-hand side of the equation is the joint distribution of the hidden and observed variables while the denominator is the marginal probability of the words observed in the corpus. Because the problem thus posed is computationally intractable, probabilistic topic models use algorithmic methods to approximate the posterior distribution, such as Gibbs samplings and variational inference (Arora et al., 2013; Blei, 2012).

Our analysis applies the simple LDA model implemented in the lda package for R to construct a synchronic summary of the ECJ's caselaw. To analyse agenda shifts through time, however, we turn to dynamic topic modelling. Whereas the plain LDA model assumes that the order of documents within the corpus does not matter, dynamic topic models allow topics to change over time by representing topics as sequences of distributions. We use the structural topic model developed by Roberts et al. (2016) and implemented in the stm package for R. Building off from the Correlated Topic Model (Blei et al., 2007), the model assumes a logistic normal prior instead of a Dirichlet prior for topic proportion. Time formally enters the document-generating process as a covariate interacting with topic prevalence:

$$
\theta_{1: D} \mid t_{1: D} \gamma, \Sigma \sim \operatorname{LogisticNormal}\left(\mu=t_{1: D} \gamma, \Sigma\right)
$$

where $t_{d}$ is the year in which document $d$ was issued; $\gamma$ is a $p \times(K-1)$ matrix of coefficients for topic proportion and $\Sigma$ is a $(K-1) \times(K-1)$ covariance matrix. As implemented in the stm package, the posterior distribution for this dynamic topic model is computed via variational Expectation Maximization.

The variety of actors granted standing under the annulment procedure allows us to assess whether topic prevalence within this particular procedure is systematically related to the type of case initiator. To do so, we construct an 
author-topic model (Rosen-Zvi et al., 2004; Blei, 2012) by replacing the time covariate in equation 2 with a plaintiff covariate. Plaintiffs are in effect treated as if they were co-authors of the cases they initiated. We distinguish seven categories of plaintiffs: (1) member state, (2) private persons (including corporations), (3) European Commission, (4) Council, (5) European Parliament, (6) EU staff and (7) others. We use the same stm implementation to compute the model.

The topics were manually labelled by the research team. The choice of label was based on (1) the words most distinctive of the topic and (2) the two decisions presenting the highest proportion of the topic. The procedure is explained in the Supplementary Materials. Because text-mining methods such as unsupervised document classification rely on complexity reduction, they require validation (Grimmer and Stewart, 2013). For that purpose we report the results of validation exercise relating our machine-generated topics to manually collected cases and case citations from a study of family reunion rulings in the Supplementary Materials. Manually collected family reunion rulings correlate with the expected machine-generated topic, but the more embedded rulings - those that are more central to the case law (based on a measure of network centrality) also feature a greater proportion of that very topic.

\subsection{Between-Corpus Comparison}

While it is computationally possible to treat all rulings as forming a single corpus and to construct a topic model (with procedure as covariate) on that basis, the resulting model would be highly influenced by procedure-specific language. Owing to the object of the procedure, infringement rulings nearly always feature words like "state", "fulfil", "obligation" and "failure". Likewise, "court", "refer", "preliminary", "proceedings", "main", "ruling" and "question" occur in virtually all preliminary rulings. These words are procedurally distinctive but substantively uninteresting from the perspective of the study of judicial agenda formation. Unless we know a priori which words are procedure-specific, so that we can remove them from the corpus, the topic model will condition on these words and produce topics that reflect procedure-specific language. This is the reason why we treat procedures as separate corpora and use corpus dissimilarity analysis ${ }^{7}$, instead of topic modelling, to investigate variations between procedures. It is then easier to determine post hoc which words capture procedure-specific structure and which capture meaningful thematic variations.

Our first corpus-level measure of dissimilarity considers what terms are distinctive of a corpus assuming that all corpora are drawn from the same popu-

\footnotetext{
${ }^{7}$ Compared to topic modelling, corpus comparison is a less developed research field. For a survey of the literature see Kilgarriff (2001) and Remus and Bank (2012).
} 
lation. Let $p_{w, c}$ be the rate at which word $w$ occurs in corpus $c$ and $C$ be the number of corpora. How distinctive of corpus $c$ word $w$ is is determined by the extent do which its count in $c$ deviates from expectation:

$$
p_{w, c}-\frac{\sum_{c=1} p_{w, c}}{C} .
$$

We compute this measure for all words appearing in our four text bodies - referrals, infringements, annulments and appeals - to mark off the set of words most distinctive of each collection of decisions.

While equation (3) should normally provide a reliable indication of the issues on which the corpora diverge most, it may be distorted by the high incidence of rare words in a small subset of documents. So, as alternative measure of corpus dissimilarity, we draw repeated, equal-sized random samples from each document collection and conduct $\chi^{2}$ and Mann-Whitney U tests on pairwise sample comparisons (Kilgarriff, 2001). We use the value of these statistics averaged over pairwise random samples to identify the most distinctive terms.

\subsection{Data Collection and Pre-processing}

We used R scripts to scrape the text of all published ECJ decisions, up to 31 December 2015, from the EUR-Lex website. ${ }^{8}$ The scraped documents add up to 11725 rulings spanning hundreds of thousands of pages of text. Figure 1 illustrates their distribution across the three procedures through time. Because references submitted by national courts may be withdrawn or formally dismissed, they do not always result in a preliminary ruling. So our analysis ignores references and considers only preliminary rulings. While it might, in principle, be interesting to explore issue attention in references and possible discrepancies with preliminary rulings, existing EU law databases often fail to provide the text of references, whether or not these have resulted in a preliminary ruling. Yet because preliminary rulings are supposed to help referring courts solve the legal question at issue, we believe that such discrepancies are rare. Withdrawals and formal dismissals also rare. ${ }^{9}$ Consequently, we believe that our focus on preliminary rulings has little effect on our results.

\footnotetext{
${ }^{8}$ More recent years were still incomplete at the time of writing.

${ }^{9}$ Only about ten references were either withdrawn or dismissed between 1961 and 1995.
} 


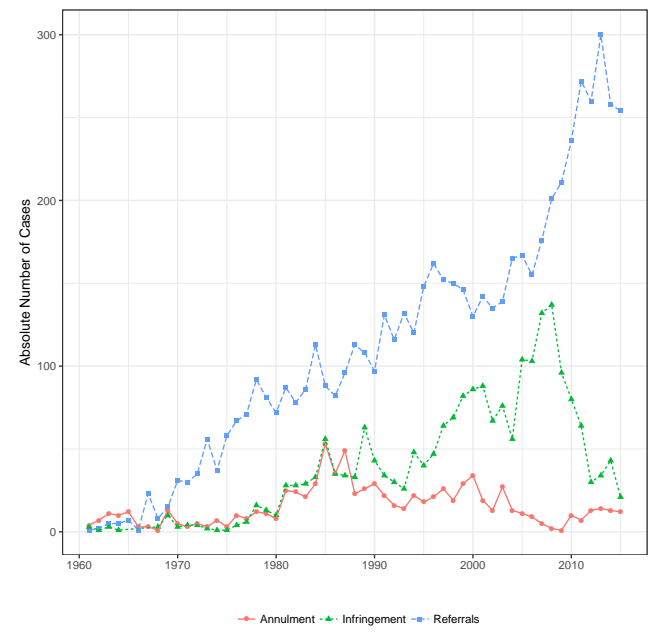

Figure 1: ECJ decisions by procedure 1961-2015. Annulment decisions include appeals against General Court rulings.

The raw documents were subject to the conventional pre-processing steps of removing punctuation, numbers, html tags, functional words and words appearing in less than five decisions before converting each corpus into a document-term matrix. To prevent our computer-assisted document classification from being influenced by case report annotations, we also removed the issue codes from the judgements. As indicated above, for the between-corpus comparison we do not the procedure-distinctive procedural terms which automatically come out as most distinctive of each procedure. ${ }^{10}$

To set the number of topics, we relied primarily on interpretability (in the Supplementary Materials we also report the results of a topic model where we select $K$ on the basis of perplexity). We found that $K=15$ resulted in easily interpretable models for infringement and annulment rulings, which form smaller corpora. For preliminary rulings, which form a much larger corpus, $K=25$ was found to strike a good balance between interpretability and specificity. The topics generated by the topic models were labelled manually by the research team. Labels were chosen after looking both at the words most characteristic of the topic and at the decision displaying the highest prevalence of the topic according to the corresponding model.

\footnotetext{
${ }^{10}$ For referrals, these are the words: "court", "preliminary", "refer", "question", "main", "proceedings", "proceeding", "judgment", "referring", "referred", "reference", "meaning" and "ruling". For infringements: "obligation", "fail", "failure", "fulfil", "state", "opinion", "obligations" and "failed". For annulments: "parliament", "commission", "european", "government", "member", "annulment", "council", "decision", "state", "contested" and "adopted".
} 


\section{Results}

\subsection{Issue Prevalence Within and Between Procedures: Static Analysis}

Labelled topics can be visualized as a network. The network in Figure 2 represents an LDA model of preliminary rulings. Node size is proportionate to the issue's overall prevalence in the corpus (measured as $\frac{\sum_{d=1} \theta_{d, k}}{D}$ ) while edge thickness denotes the degree of correlation among topics (as calculated from their $\beta$ distributions over the vocabulary). (The complete set of unlabelled topics together with the words displaying the highest $\beta$ value are reported in the Supplementary Materials.) Visualizing a topic model this way facilitates the identification of issues clustering around broader themes. In Figure 2 policy, customs, taxation and labour market regulations come out as the most prevalent issues. On closer examination, though, two distinct clusters of issues become apparent. In the lower left part of the network are core internal market issues: labelling, goods, import, export, trademark, customs, tariffs, corporate taxation and services. In the right region are the welfare, law and order and administrative law issues: labour, social security, residence and immigration, criminal matters, public procurement and recognition of foreign judgements. 


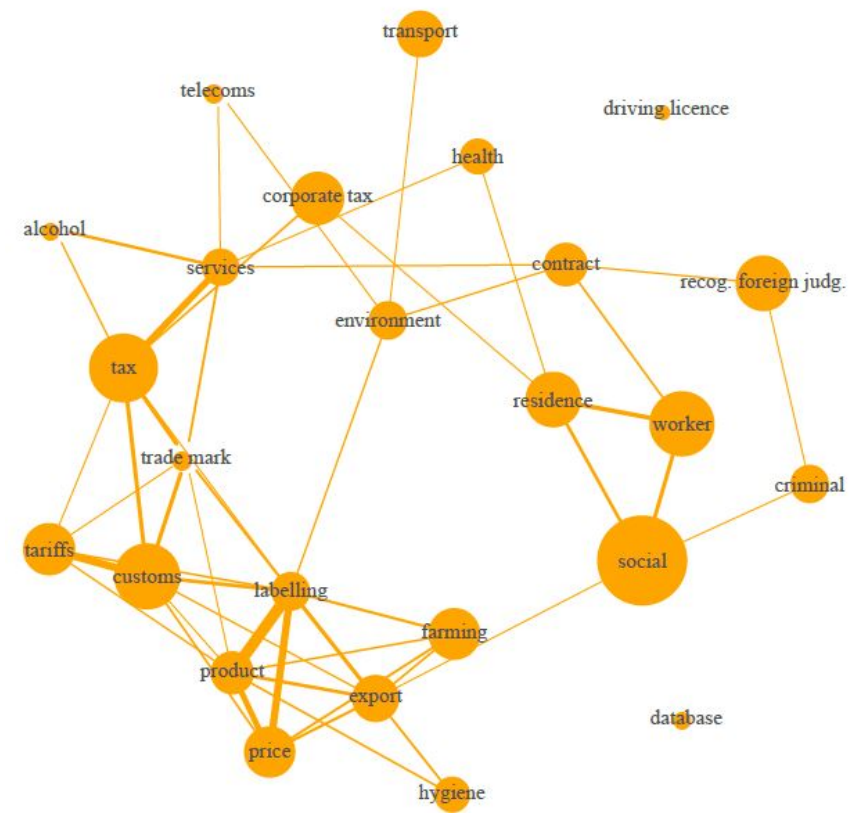

Figure 2: Topic model of preliminary rulings from Figure 11 with labelled topics represented as a network.

Note: Node size denotes topic prevalence across the entire set of documents. Edge thickness denotes correlation among topics.

The saliency of the internal market theme is consistent with the perception that "dull tax cases, consumer protection actions, common customs tariff classification disputes, trans-border enforcement of small civil claims, companies' shareholders quarrels and so on" represent a large chunk of the ECJ's caseload (Bobek, 2013). Yet preliminary rulings are about more than just market regulations. As Figure 2 illustrates, welfare benefits and migrants' and workers' rights form another important theme.

How do preliminary rulings compare to the other procedures? Figure 3 illustrates topic models of infringement and annulment proceedings. The infringement model features one topic, "monarchies", which simply captures language in cases brought by or against member states with a constitutional monarchy. ${ }^{11}$ Overall though, the topics are readily interpretable and meaningful. Internal market and environmental topics clearly dominate infringement proceedings. Internal market issues include free movement of goods, workers, services and capital along with

\footnotetext{
${ }^{11}$ The case with the highest $\theta_{\text {monarchies }}$ is Kingdom of Spain $v$ United Kingdom of Great Britain and Northern Ireland over Gibraltar, one of the rare infringement actions initiated by a national government. Unsurprisingly, less than a handful of decisions have a $\theta_{\text {monarchies }}$ larger than 0.5 .
} 
tariffs, competition and public procurement. Issues pertaining to the harmonization of hygiene regulations and the liberalization of the telecoms and passenger rail market are part of the same internal market theme. Environmental issues encompass conservation and waste water treatment. The saliency of the internal market theme is consistent with previous research linking the rise in infringement actions in the 1980s and 1990s to the European Commission's internal market agenda (Tallberg, 1999). Compared to referral proceedings, infringement cases appear more cohesive and less diverse. Striking is the low attention to welfare, residence and social rights, which are relatively prominent in preliminary rulings. This is consonant with our hypothesis that the referral procedure is more inclusive and affords individuals, notably the economically and politically disadvantaged, greater influence over the European Court's agenda (Alter, 2006; Keohane et al., 2000; Caporaso and Tarrow, 2009; Cichowski, 2007; Conant, 2006). Next to internal market themes, environmental matters form the most prevalent issue in infringement actions. On core internal market issues, on the other hand, referral and infringement cases show a significant overlap. Here at least, private enforcement may be an effective substitute or complement for prosecution by Commission officials (Kelemen, 2012; Börzel, 2006; Tallberg, 1999). Taxation, too, is a domain where the priorities of the Commission and the interests of private litigants largely overlap (Genschel and Jachtenfuchs, 2011).

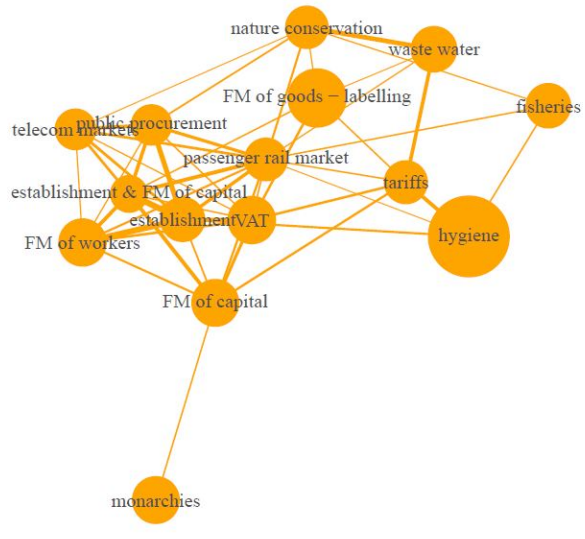

(a) Infringement procedure.

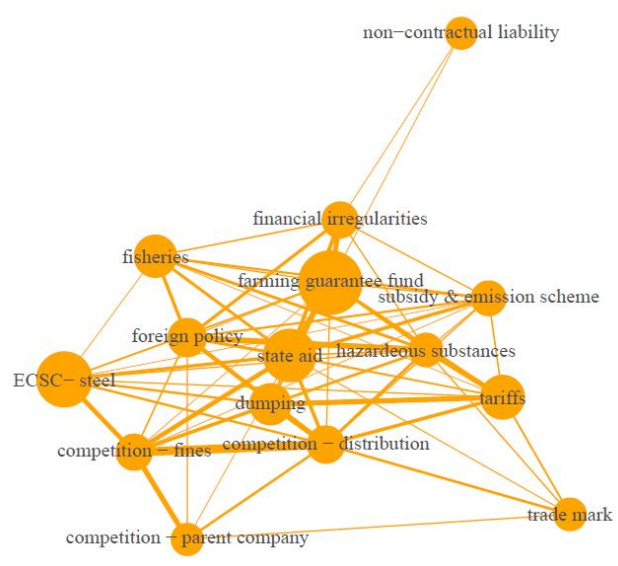

(b) Annulment procedure.

Figure 3: Topic models (latent Dirichlet allocation) with labelled topics for infringement and annulment.

Note: Node size denotes overall topic prevalence across the entire set of decisions. Edge thickness denotes correlation among topics. 
Annulment cases (Figure 3b) address various EU policies: anti-dumping measures, the regulation of fisheries, the common agricultural policy (CAP), steel production (under the European Coal and Steel Community), the internal market (tariffs and hazardous substances) and the common foreign and security policy (CFSP). Several topics capture aspects of the EU competition policy: the application of competition rules to distribution systems and parent companies and the fines imposed by the European Commission, whose magnitude parties often challenge. As with the referral procedure, greater inclusiveness seems to result in greater issue heterogeneity.

Corpus-level analysis confirms the asymmetry in issue attention between referral and infringement proceedings regarding welfare and environmental protection. Figure 4 displays a comparison wordcloud, where the size of the words is proportionate to procedural distinctiveness. We see that the terms "employ", "benefits", "pension" and "social" occur disproportionately more in preliminary rulings whereas "environment", "waste", "water", "pollution", "protect" and "bird" are more characteristic of infringement decisions. Member states are often dragged before the Court of Justice for failing to transpose EU directives adequately (Tallberg, 1999; Craig and Burca, 2015, 444). This is attested by the words "transpose", "transposition" and "implementation". Attesting to the large number of competition cases brought under the annulment procedure is the word "fine"-this word is distinctive of annulment compared to both infringement and preliminary rulings. 


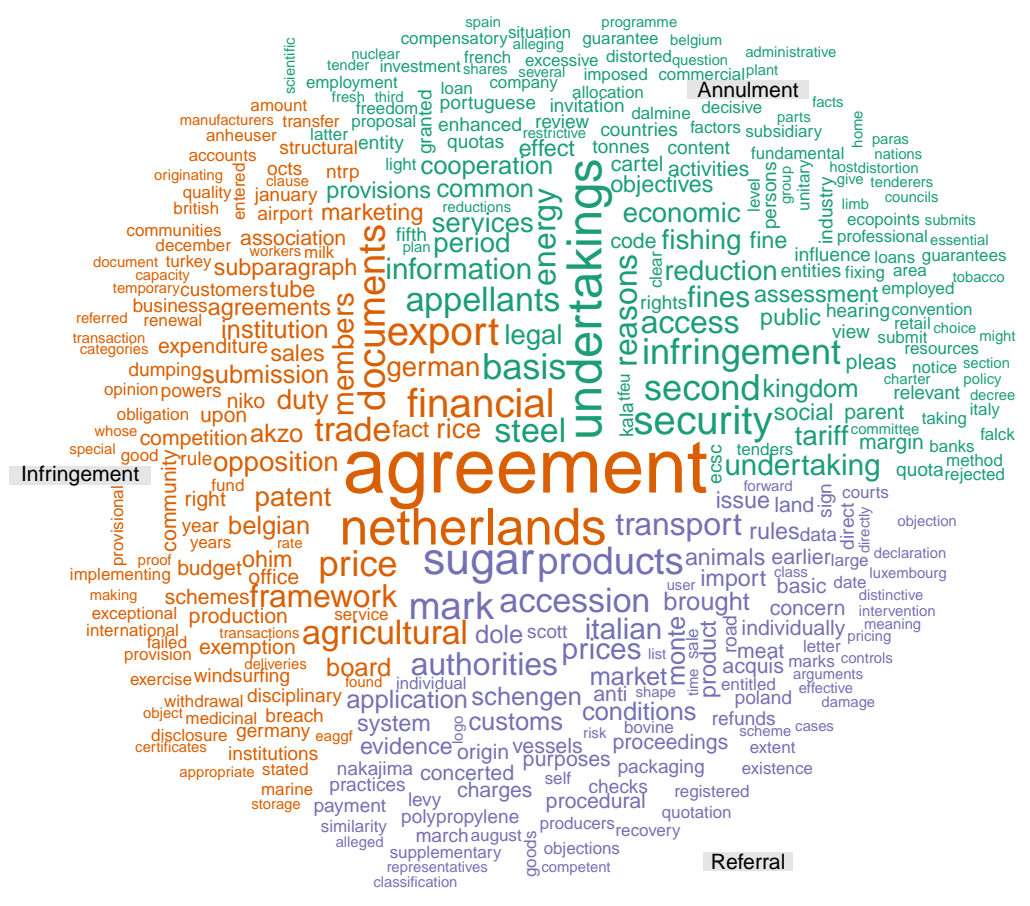

Figure 4: Corpus dissimilarity.

Note: The plot illustrates the words most distinctive of each procedure. We exclude procedure-specific words.

Figure 5 shows the most dissimilar words in pairwise comparison of bootstrapped samples of the two corpora (the results of referral-annulment and infringementannulment comparisons are reported in the Supplementary Materials). Here again, we see that "waste", "water" and "directives" are more characteristic of infringement proceedings whereas "benefits" and "employment" are more distinctive of preliminary rulings. The difference in the average frequency of the word "agriculture" in Figure 14 in the Supplementary Materical confirms that the common agricultural policy is more frequently litigated in the annulment procedure. Both the $\chi^{2}$ and Mann-Whitney U test point to significant pairwise corpus dissimilarities. Averaged over the 10000 bootstrapped samples, p-values for these statistics are $p<0.001$ in all three pairwise comparisons.

Figure 6 shows topic proportion across seven categories of plaintiffs in annulment proceedings. By showing how issue emphasis varies across litigant types, it lends additional support to the inclusiveness hypothesis. Private and public 


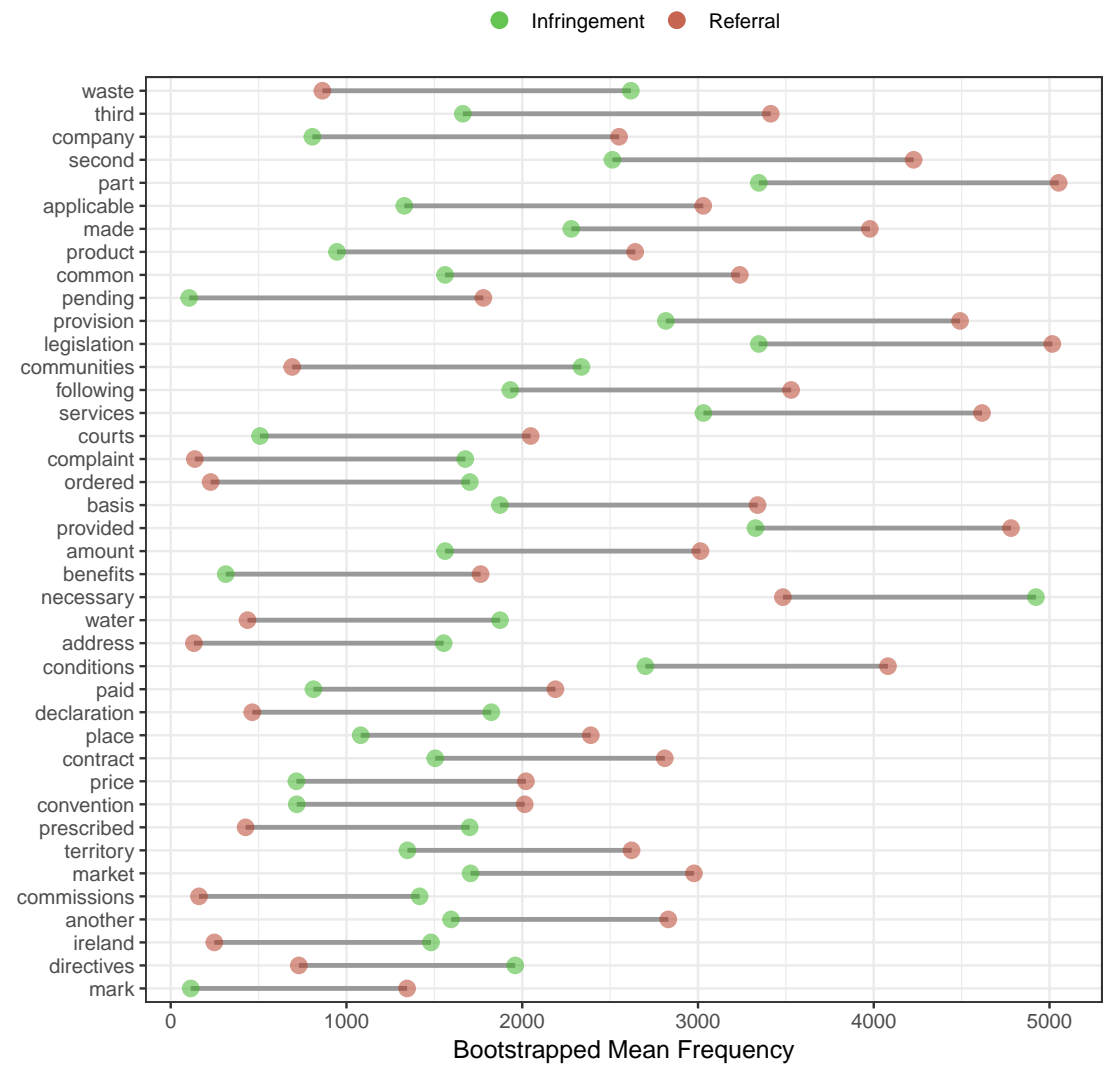

Figure 5: Corpus dissimilarities: Infringement - Referral

Note: The plot displays the most distinctive terms in pairwise comparisons of the procedures. Words are sorted by bootstrapped mean difference. Figure excludes procedure specific words. 
litigants emphasise different issues, which reflects the distinct interests they seek to defend. National governments mostly bring cases pertaining to the agricultural guarantee fund, state subsidies to domestic industries, border crossing and oversea territories. Private litigants use the annulment procedure to challenge EU regulatory decisions on competition, dumping and trademarks. Until the ECSC was absorbed into the European Union, private litigants were also more likely to bring cases in connection with the regulation of coal and steel industries. EU institutions tend to litigate the same issues. Yet the European Parliament is disproportionately likely to litigate border crossing issues while the cases in which the European Commission is the plaintiff are more likely to be about state aid. EU civil servants, meanwhile, mostly bring employment disputes.
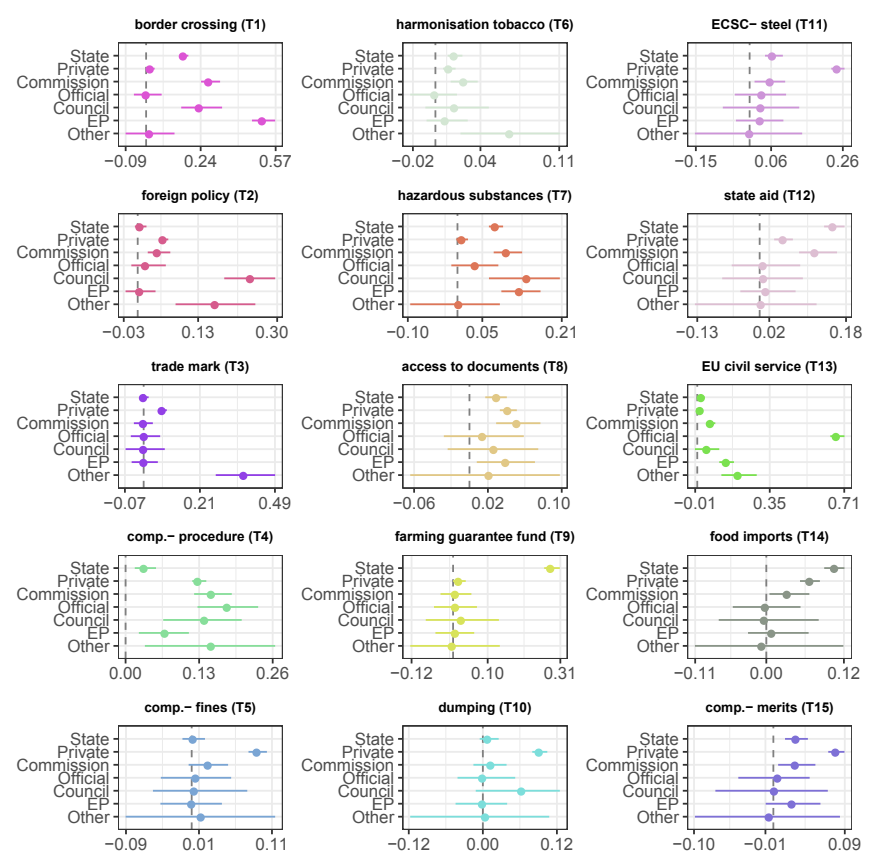

Figure 6: Author-topic model of annulment cases $(K=15)$.

Note: Plot depicts topic proportion for seven categories of case initiators. Horizontal bar denotes 95 per cent confidence interval. 


\subsection{Dynamic Analysis}

The foregoing textual analysis is static in that it models ECJ decisions without consideration of the date at which they were issued. However, in order to investigated issue stability over time, we turn to dynamic topic modelling. Figure 7 illustrates a dynamic topic model of preliminary rulings. The topic labelled "Constitutional", which has no equivalent in the static model of preliminary rulings, is defined by terms that include "community" (as in "Community law"), "provisions" and "effect" (as in "direct effect"). ${ }^{12}$

Figure 7 indicates that, relative to other topics, attention to constitutional questions has declined dramatically over time. Constitutional went from most prevalent topic in the 1960s to marginal one after the 1980s. This evolution is in line with the dominant narratives of the European integration process in EU studies. These narratives describe the 1960s and early 1970s as the "foundational" period during which the ECJ "constitutionalised" EU law (Weiler, 1991; Sweet and Brunell, 1998). The foundational phase laid the ground for the subsequent expansion of EU law litigation to new domains (Alter, 2001; Sweet and Brunell, 1998). It is also consistent with our hypothesis that more inclusive procedures enable international judges to shape their dockets by socialising new litigants into the development and expansion of supranational law, thereby making issue attention more dynamic and less stable over time. The constitutional rulings signalled to potential litigants the opportunities offered by EU law litigation to challenge domestic legislation. As litigants responded to the signal more cases were litigated across a broader set of policy areas. Next to constitutional principles, trade, particularly non-tariff barriers, represented the most important item on the Court's agenda in the early period. Later, corporate taxation, trademarks, consumer protection, citizenship, environmental protection, labour regulation, telecommunications, patents, intellectual property, establishment freedom (notably the mutual recognition of professional certifications), asylum, EU funding, public procurement and VAT became more salient. Surprisingly, attention to social policy questions (benefits, pensions) appear to have declined over time, although some questions ordinarily falling under the social policy heading may

\footnotetext{
${ }^{12}$ The classification of landmark constitutional rulings amakes intuitive sense. Simmenthal, a case arising from a dispute over meat imports in which the ECJ held that every domestic court had the power to set aside domestic legislation contrary to EU law, is classified as 63 per cent constitutional. Costa $v$ ENEL, in which the ECJ first spelled out the principle of supremacy of EU law, is 48 per cent constitutional. Factortame $I$, the first time an act of the British Parliament was declared contrary to EU law, shows a similar topic proportion (47 percent). So too does Van Gend en Loos, the 1963 ruling that gave birth to the doctrine of direct effect (43 per cent constitutional). At 30 per cent the topic proportion for Francovich, in which the ECJ established the principle of state liability for failure to transpose EU directives, is somewhat lower, although still plausible.
} 
be captured by topic 12 (labour). ${ }^{13}$

\footnotetext{
${ }^{13}$ This intuition is supported by our comparison with issue codes from the official case report in Figure 16b.
} 

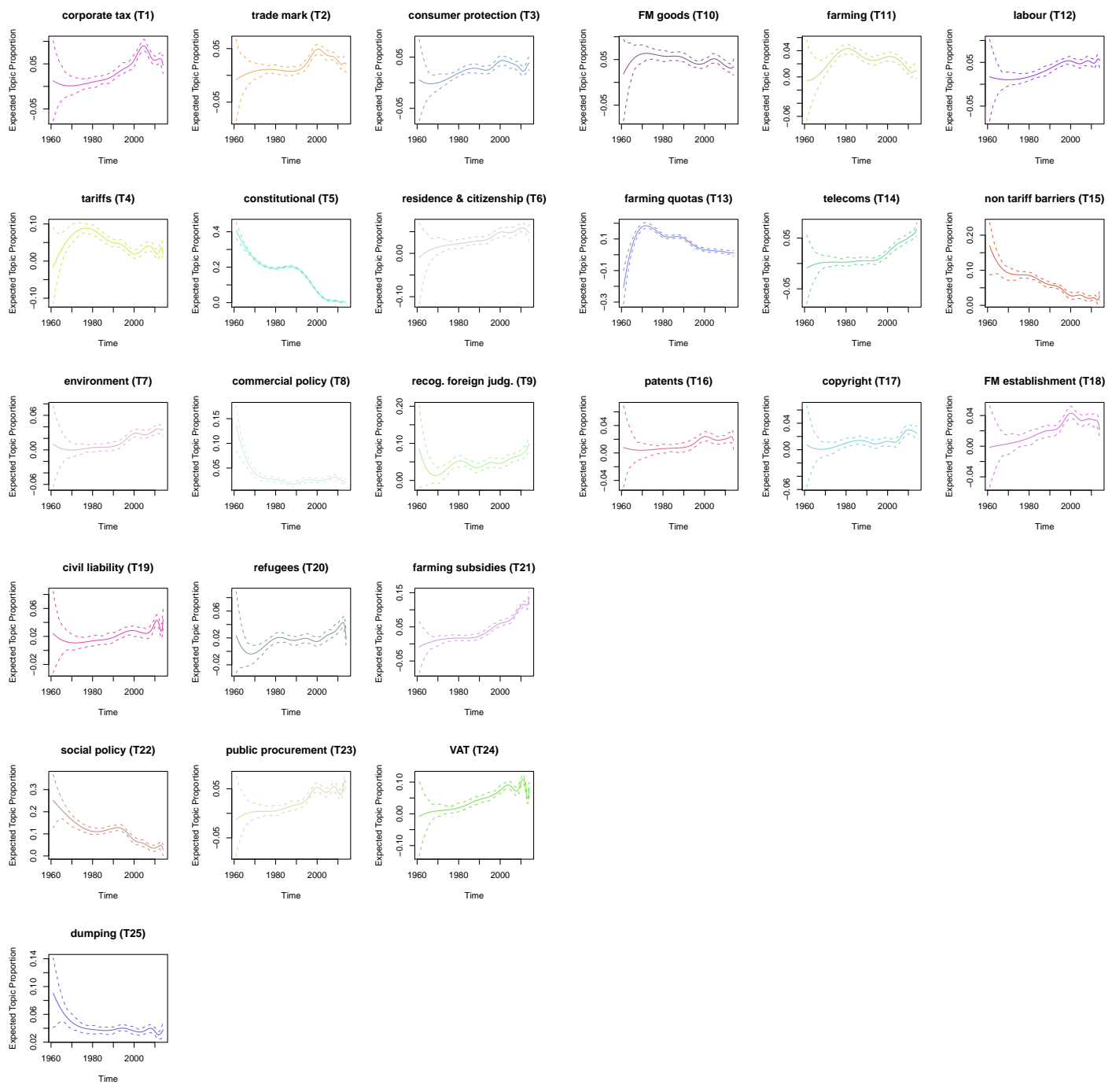

Figure 7: Topic proportion by year from dynamic topic model $(K=25)$ of preliminary rulings.

Note: Dashed lines show 95 per cent confidence interval. 

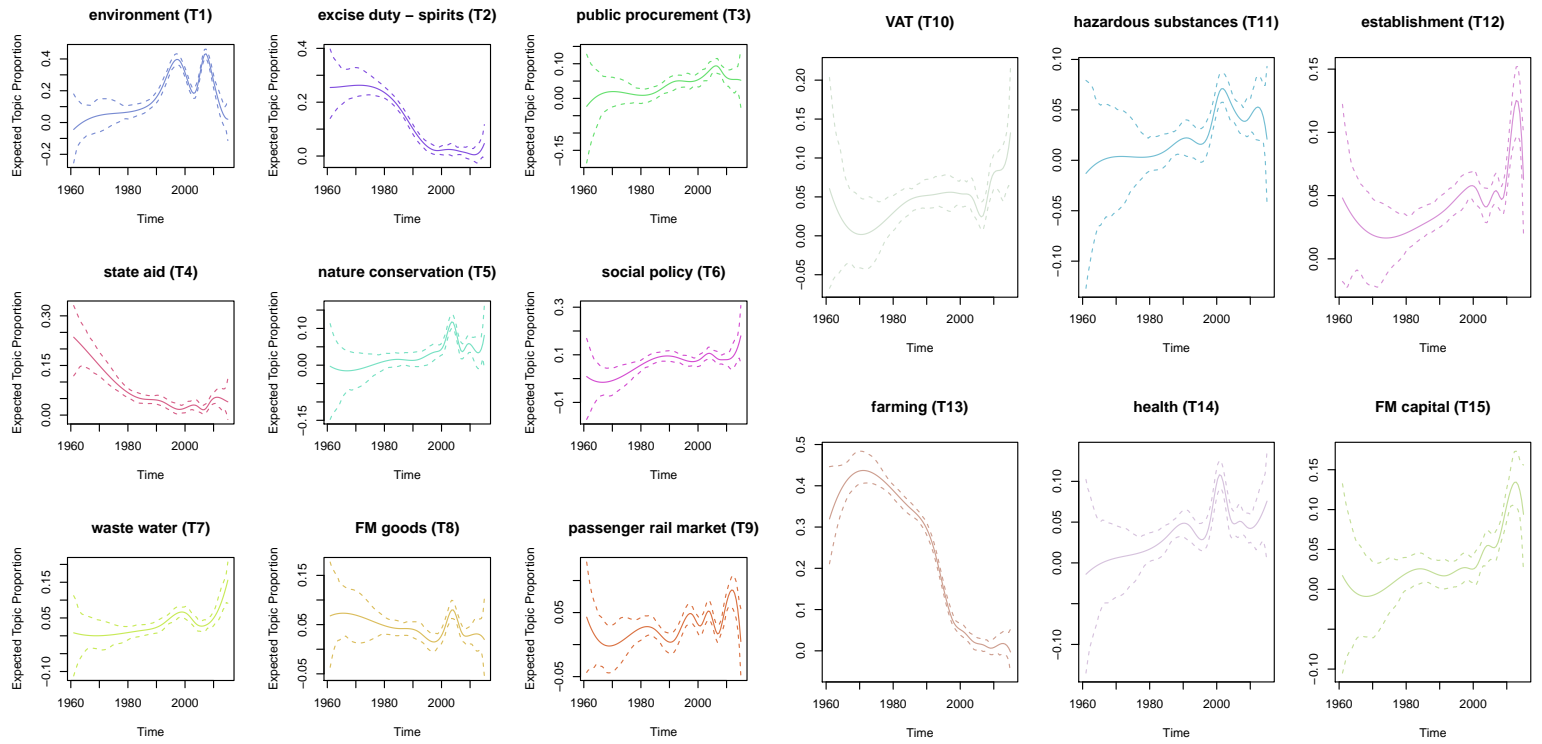

Figure 8: Topic proportion by year from dynamic topic model $(K=15)$ of infringement decisions.

Compared to referrals, issue prevalence in infringement cases looks more stable through time (Figure 8). Some topics show short-term blips in issue attention, presumably as a result of the Commission going after multiple member states at the same point in time after the deadline for transposition of EU legislation has expired. Yet, save for excise duty, farming and state aid, long-term trends suggest less abrupt and less pronounced change in issue prevalence, as we would expect in light of the procedure's lower degree of inclusiveness. Because only the Commission has standing to initiate litigation, the Court cannot use its case law to send signals and socialize new litigants into the system. 

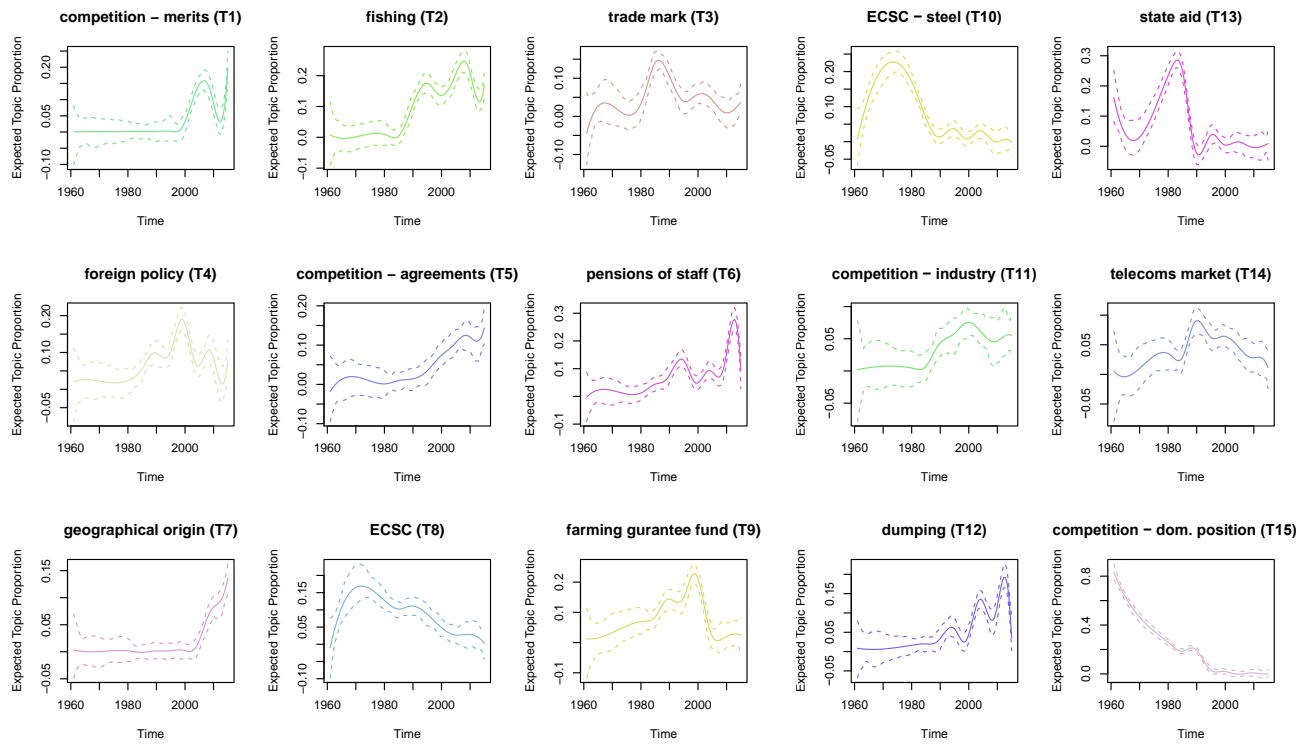

Figure 9: Topic proportion by year from dynamic topic model $(K=15)$ of annulment decisions.

It is for annulment cases that topic proportion shows the greatest temporal variation, as illustrated in Figure 9. All fifteen topics show sharp variations, whether it is trade mark, foreign policy, dumping or competition-related issues. This, again, supports the hypothesis that broader access rules and greater litigant heterogeneity have the effect of lowering issue stability. At least in terms of the diversity of litigants, the annulment procedure is the most inclusive and maybe the most responsive to the ECJ's doctrinal signals.

\section{Discussion}

Our analysis sought to advance our understanding of agenda formation on international courts by looking at patterns of issue attention on the ECJ. Expanding on insights from the literature on US courts (Jacobi, 2008; Baird and Jacobi, 2009) and international adjudication (Keohane et al., 2000; Alter, 2006, 2001, 2012; Conant, 2006), our analysis focused on how access rules shape issue diversity and stability. We argued that more inclusive access rules granting standing to a broad set of actors, especially private ones, should coincide with greater issue heterogeneity and greater temporal variably as new litigants are socialised in the judicial process. We exploited the high degree of institutional variation in the ECJ's access rules to assess these hypotheses. Using natural language processing techniques and analysing the entire universe of ECJ decisions up to 2015, we 
found that the more inclusive referral and annulment procedures are associated with higher issue diversity and lower issue stability, whereas the less inclusive infringement procedure exhibits both greater issue cohesiveness and greater issue stability over time.

While illustrating how text-mining tools can be applied to construct measures of issue prevalence from large collections of judicial texts, our results are potentially relevant to research on other international judicial bodies with access rules that either partly or fully overlap with the ECJ's. Alter (2012) lists 11 ECJ-style international courts with procedures and rules of standing similar to those examined in the present analysis. ${ }^{14}$ Nine of these courts have a procedure similar to the ECJ's infringement procedure which allows a supranational commission to file suits against non-compliant member states. Ten of them have a preliminary ruling system of national court referrals while all provide for administrative review along the lines of the ECJ's annulment procedure. Though largely modelled after the ECJ, most of these courts are still far from matching its power and institutional prominence. Compared to the ECJ their caseload is usually modest. Yet they are some exceptions. The Andean Tribunal of Justice, for example, has seen a rapid increase in its caseload, mostly driven by the rise in referrals from national courts (Alter, 2012; Alter and Helfer, 2010). Beyond these emulations of the ECJ, there are other institutional courts where agenda formation may follow the procedural constraints highlighted in the present study. The Inter-American Court of Human Rights has a gatekeeping setup similar to the infringement procedure, where a supranational commission decides what human rights complaints should be referred to the judges. A similar system existed before the European Court of Human Rights until the introduction of direct private access in 1998. As with social policy issues before the ECJ, our analysis suggests that some issues may be less likely to reach adjudicators when access is controlled by a non-judicial commission than when private individuals and domestic judges have the initiative.

Going forward, we see room for further research in two directions. First, we think that the approach presented here is worth applying to other international judicial bodies, if only to check whether our hypotheses hold for these tribunals, too. Second, we think future research should look for ways to shed light on the exact causal mechanism linking the litigants' preferences and the judges' doctrinal

\footnotetext{
${ }^{14}$ Ordered by year the court became operational these are: the Benelux Court (became operational in 1974), the Andean Tribunal of Justice (1984), the Central American Court of Justice (1992), the European Free Trade Area Court (1992), the West African Economic and Monetary Union (1995), the Common Market for East African States (1998), the Central African Monetary Community (2000), the East African Community Court (2001), the Caribbean Court of Justice (2001), the Court of Justice of the Community of West African States (2001) and the Southern African Development Community (2005).
} 
signals to variation in access rules. 


\section{References}

Alter, K. J. (2001). Establishing the supremacy of European law: The making of an international rule of law in Europe. Oxford University Press Oxford.

Alter, K. J. (2006). Private litigants and the new international courts. Comparative Political Studies 39(1), 22-49.

Alter, K. J. (2012). The global spread of european style international courts. West European Politics 35(1), 135-154.

Alter, K. J. and L. R. Helfer (2010). Nature or Nurture? Judicial Lawmaking in the European Court of Justice and the Andean Tribunal of Justice. International Organization 64(04), 563-592.

Arora, S., R. Ge, Y. Halpern, D. Mimno, A. Moitra, D. Sontag, Y. Wu, and M. Zhu (2013). A practical algorithm for topic modeling with provable guarantees. In International Conference on Machine Learning, pp. 280-288.

Baird, V. and T. Jacobi (2009). Judicial agenda setting through signaling and strategic litigant responses. Wash. UJL 89 Pol'y 29, 215.

Baird, V. A. (2004). The effect of politically salient decisions on the us supreme court's agenda. The Journal of Politics 66 (3), 755-772.

Blei, D. M. (2012). Probabilistic topic models. Communications of the ACM 55(4), 77-84.

Blei, D. M., J. D. Lafferty, et al. (2007). A correlated topic model of science. The Annals of Applied Statistics 1(1), 17-35.

Blei, D. M., A. Y. Ng, and M. I. Jordan (2003). Latent dirichlet allocation. Journal of machine Learning research 3(Jan), 993-1022.

Bobek, M. (2013). Of feasibility and silent elephants: The legitimacy of the court of justice in the eyes of national courts. In M. Adams, H. De Waele, J. Meeusen, and G. Straetman (Eds.), Judging Europe's Judges: The Legitimacy of the Case Law of the European Court of Justice, pp. 197. Hart Publishing.

Börzel, T. A. (2003). Guarding the treaty: the compliance strategies of the european commission. In T. A. Börzel and R. A. Cichowski (Eds.), The state of the European Union, Volume 6, pp. 197-220. Oxford University Press.

Börzel, T. A. (2006). Participation through law enforcement: the case of the european union. Comparative Political Studies 39(1), 128-152. 
Caldeira, G. A., J. R. Wright, and C. J. W. Zorn (1999, October). Sophisticated voting and gate-keeping in the supreme court. JLEO 15(3), 549-572.

Cameron, C. M. and L. A. Kornhauser (2013). Bargaining on Appellate Courts.

Caporaso, J. A. and S. Tarrow (2009). Polanyi in brussels: Supranational institutions and the transnational embedding of markets. International Organization 63(4), 593-620.

Chang, J., S. Gerrish, C. Wang, J. L. Boyd-Graber, and D. M. Blei (2009). Reading tea leaves: How humans interpret topic models. In Advances in neural information processing systems, pp. 288-296.

Cichowski, R. (2007). The European Court and Civil Society: Litigation, Mobilization and Governance. Cambridge University Press.

Conant, L. (2006). Individuals, courts, and the development of european social rights. Comparative Political Studies 39(1), 76-100.

Craig, P. and G. d. Burca (2015, November). EU Law: Text, Cases, and Materials (5 edition ed.). Oxford ; New York: Oxford University Press.

De Somer, M. (2019). The Court's Role in Processes of European Integration. Springer.

Edelman, P. H. and J. Chen (2007). The most dangerous justice rides into the sunset. Const. Comment. 24, 199.

Epstein, L., J. A. Segal, and T. Johnson (1996). The Claim of Issue Creation on the US Supreme Court. American Political Science Review, 845-852.

Gabel, M., C. Carrubba, C. Ainsley, and D. Beaudette (2012). Of courts and commerce. The Journal of Politics 74 (4), 1125-1137.

Genschel, P. and M. Jachtenfuchs (2011). How the european union constrains the state: Multilevel governance of taxation. European Journal of Political Research 50 (3), 293-314.

Grimmer, J. and B. M. Stewart (2013, January). Text as Data: The Promise and Pitfalls of Automatic Content Analysis Methods for Political Texts. Political Analysis.

Harlow, C. and R. Rawlings (2006). Accountability and law enforcement: The centralised eu infringement procedure'(2006). European Law Review 31, 447. 
Hix, S. (2011, March). The Political System of the European Union (3rd edition edition ed.). Basingstoke: Palgrave Macmillan.

Hix, S., A. Noury, and G. Roland (2009, March). Voting patterns and alliance formation in the European Parliament. Philosophical Transactions of the Royal Society of London B: Biological Sciences 364(1518), 821-831.

Huber, J. D. (1992). Restrictive Legislative Procedures in France and the United States. The American Political Science Review 86(3), 675-687. ArticleType: research-article / Full publication date: Sep., 1992 / Copyright (c) 1992 American Political Science Association.

Jacobi, T. (2008). The judicial signaling game: How judges shape their dockets. Supreme Court Economic Review 16(1), 1-38.

Kastellec, J. P. and J. R. Lax (2008). Case Selection and the Study of Judicial Politics. Journal of Empirical Legal Studies 5(3), 407-446.

Kelemen, D. R. and T. Pavone (2016). Mapping european law. Journal of European Public Policy 23(8), 1118-1138.

Kelemen, R. D. (2012). Eurolegalism and democracy. JCMS: Journal of Common Market Studies $50(\mathrm{~s} 1), 55-71$.

Keohane, R. O., A. Moravcsik, and A.-M. Slaughter (2000). Legalized Dispute Resolution: Interstate and Transnational. International Organization 54(03), 457-488.

Kilgarriff, A. (2001). Comparing corpora. International journal of corpus linguistics $6(1), 97-133$.

Martin, A. D. and K. M. Quinn (2002). Dynamic ideal point estimation via markov chain monte carlo for the us supreme court, 1953-1999. Political Analysis $10(2), 134-153$.

Mimno, D., H. M. Wallach, E. Talley, M. Leenders, and A. McCallum (2011). Optimizing semantic coherence in topic models. In Proceedings of the conference on empirical methods in natural language processing, pp. 262-272. Association for Computational Linguistics.

Perry, H. W. (2009). Deciding to decide: agenda setting in the United States Supreme Court. Harvard University Press.

Remus, R. and M. Bank (2012). Textual characteristics of different-sized corpora. In The 5th Workshop on Building and Using Comparable Corpora, pp. 148. 
Roberts, M. E., B. M. Stewart, and E. M. Airoldi (2016). A model of text for experimentation in the social sciences. Journal of the American Statistical Association 111(515), 988-1003.

Rosen-Zvi, M., T. Griffiths, M. Steyvers, and P. Smyth (2004). The author-topic model for authors and documents. In Proceedings of the 20th conference on Uncertainty in artificial intelligence, pp. 487-494. AUAI Press.

Scheppele, K. L. (2005). Democracy by judiciary: Or, why courts can be more democratic than parliaments. Rethinking the rule of law after communism, $25-60$.

Schmidt, S. K. (2012). Who cares about nationality? the path-dependent case law of the ecj from goods to citizens. Journal of European Public Policy 19(1), $8-24$.

Shapiro, C. (2008). Coding complexity: Bringing law to the empirical analysis of the supreme court. Hastings LJ 60, 477.

Smith, M. (2008). Enforcement, monitoring, verification, outsourcing: the decline and decline of the infringement process. European Law Review 33(6), 777-802.

Stone Sweet, A. (2004). The Judicial Construction of Europe. Oxford [u.a.]: Oxford University Press.

Sweet, A. S. and T. L. Brunell (1998). Constructing a supranational constitution: Dispute resolution and governance in the european community. American Political Science Review 92(1), 63-81.

Tallberg, J. (1999). Making states comply: the European Commission, the European Court of Justice $\&$ the enforcement of the internal market, Volume 109. Lund University.

Voeten, E. (2007). The Politics of International Judicial Appointments: Evidence from the European Court of Human Rights. International Organization 61(04), 669-701.

Wallach, H. M., I. Murray, R. Salakhutdinov, and D. Mimno (2009). Evaluation methods for topic models. In Proceedings of the 26th annual international conference on machine learning, pp. 1105-1112. ACM.

Weiler, J. H. H. (1991). The Transformation of Europe. Yale L.J., 2403-2483. 


\section{A Supplementary materials}

\section{A.1 Labelling Topics}

Topics were labelled by looking at their most distinctive words and by inspecting the rulings with the highest prevalence. Shown in Figure 10 are two examples of unlabelled topics from a $K=25$ LDA model of preliminary rulings. Intuitively, with words such as "television", "copyright" and "communication", topic 1 seems to be about intellectual property in the context of television broadcasting whereas, with words like "capital", "income", "resident", "taxation", "dividends" and "shares", topic 14 seems to be about corporate taxation.
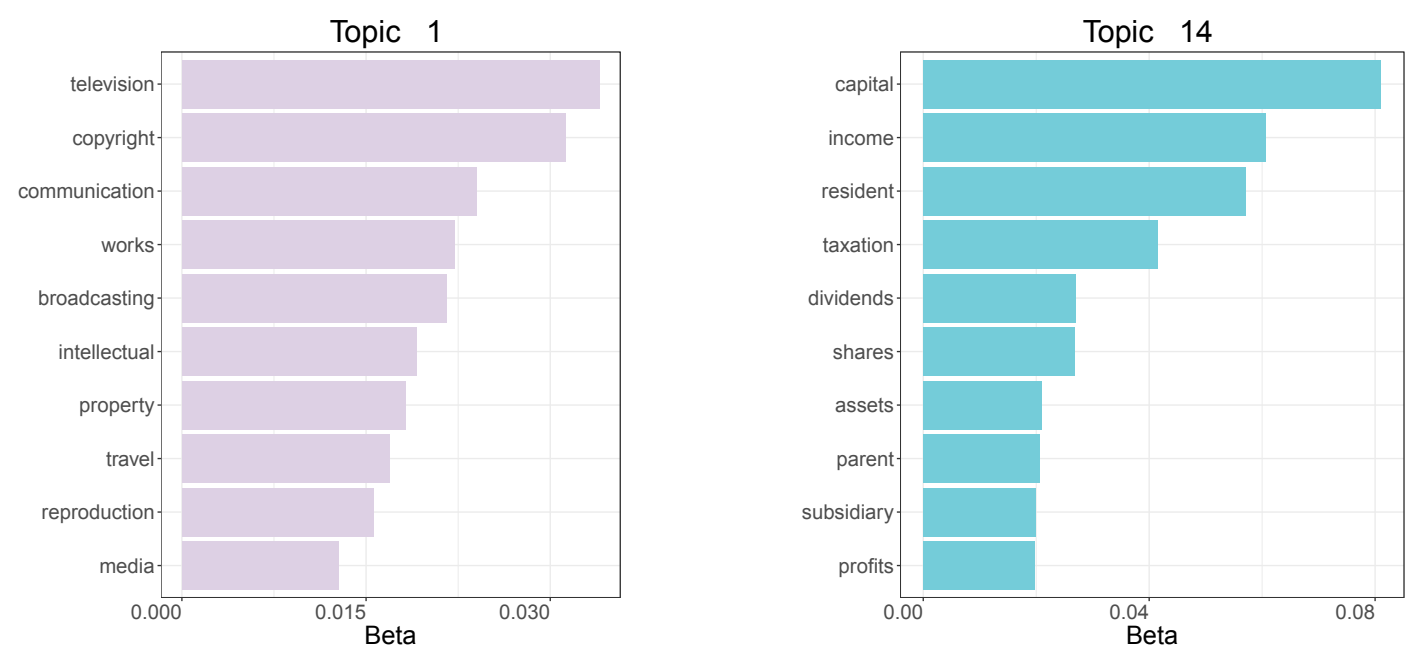

Figure 10: Two topics from a $K=25$ topic model (latent Dirichlet allocation) of preliminary rulings.

Note: Topics are represented by their ten most specific terms. Terms with larger $\beta$ values are more characteristic of the topic.

Inspecting the opinion with the highest proportion of the topic-the highest $\theta_{k}-$ can help in interpreting the terms that define it. As an illustration, consider topic 14 . The decision with the highest $\theta_{14}$ value $(0.95)$ turns out to be Test Claimants in the FII Group Litigation $v$ Commissioner of Inland Revenue, a 2012 Grand Chamber ruling on a reference from the High Court of Justice of England and Wales. We quote the first paragraphs of the facts section of the decision:

The High Court of Justice of England and Wales, Chancery Division, seeks, first, to obtain clarification regarding paragraph 56 of the 
judgment in Test Claimants in the FII Group Litigation and point 1 of its operative part. It recalls that the Court of Justice held, in paragraphs 48 to 53, 57 and 60 of that judgment, that national legislation which applies the exemption method to nationally-sourced dividends and the imputation method to foreign-sourced dividends is not contrary to Articles 49 TFEU and 63 TFEU, provided that the tax rate applied to foreign-sourced dividends is not higher than the rate applied to nationally-sourced dividends and that the tax credit is at least equal to the amount paid in the Member State of the company making the distribution, up to the limit of the tax charged in the Member State of the company receiving the dividends. ${ }^{15}$

The decision is clearly about corporate taxation in the context of the internal market, which is what the terms characterising topic 14 suggest too. Looking at these and other rulings with high prevalence of topic 14, it was labelled "corporate tax".

${ }^{15}$ Judgment of 13 November 2012, C-35/11, para. 21. 


\section{A.2 Topics: Static and Dynamic}
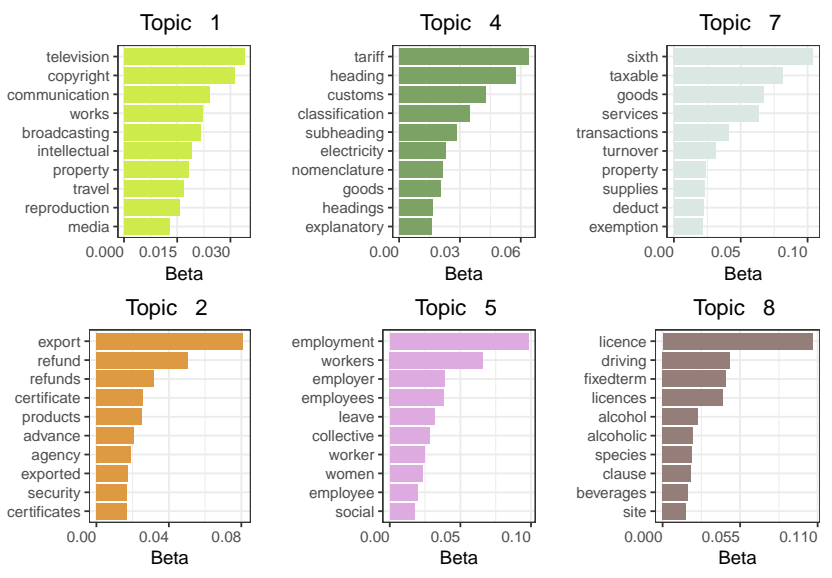

Topic 3
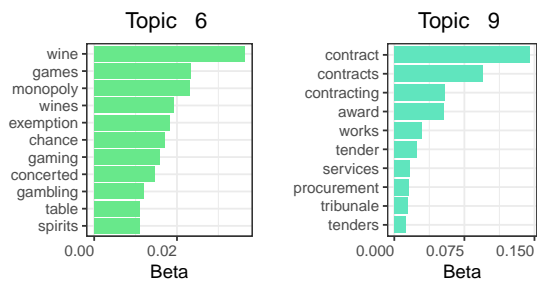

Figure 11: Unlabelled topics from a $K=25$ topic model (latent Dirichlet allocation) of preliminary rulings.

Note: Topics are represented by their ten most specific terms. Terms with larger $\beta$ values are more characteristic of the topic. 

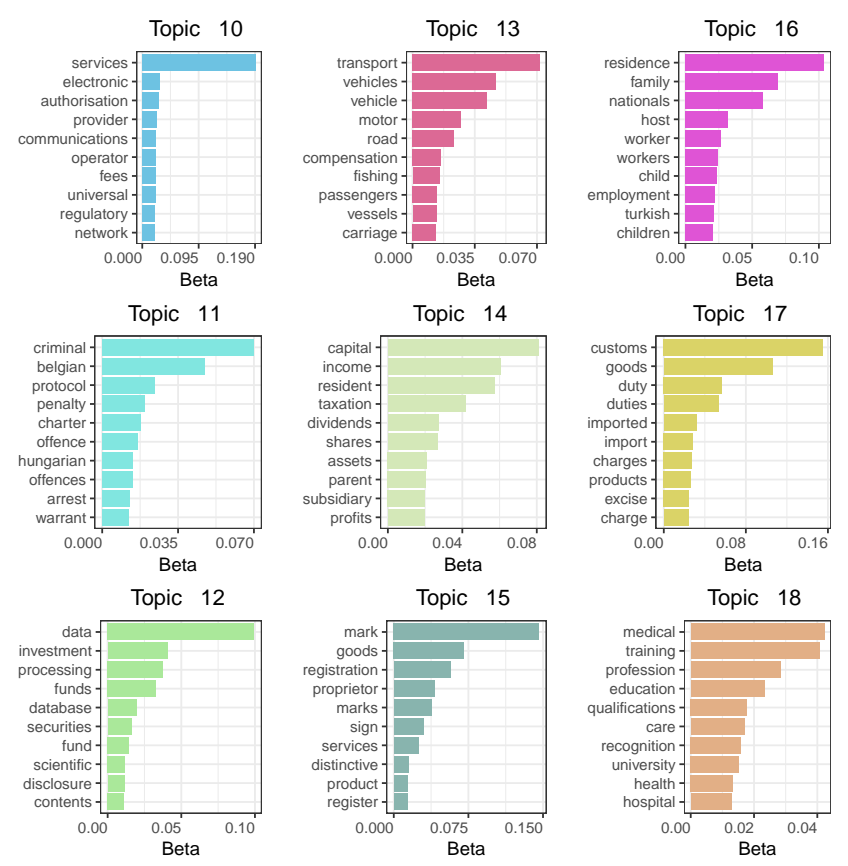

Figure 11: (cont.) 
Topic 19

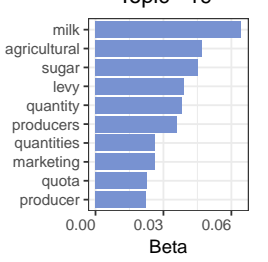

Topic 20

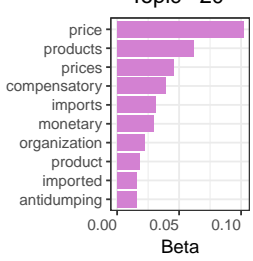

Topic 21

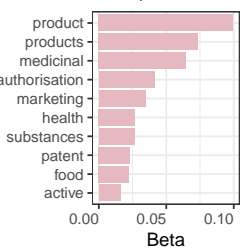

Topic 22

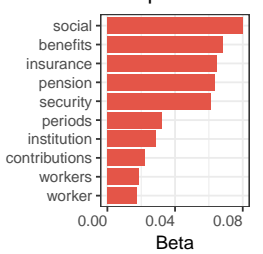

Topic 23

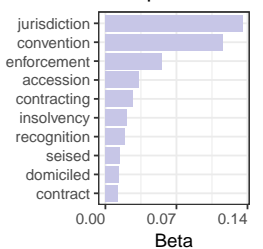

Topic 24

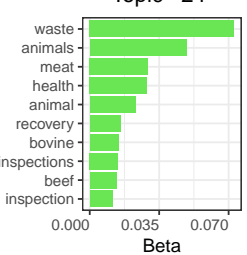

Topic 25

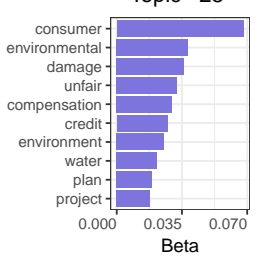

damage

mpensation -
credit -

ironment -

plan -

$0.000 \quad 0.035 \quad 0.070$

Figure 11: (cont.) 


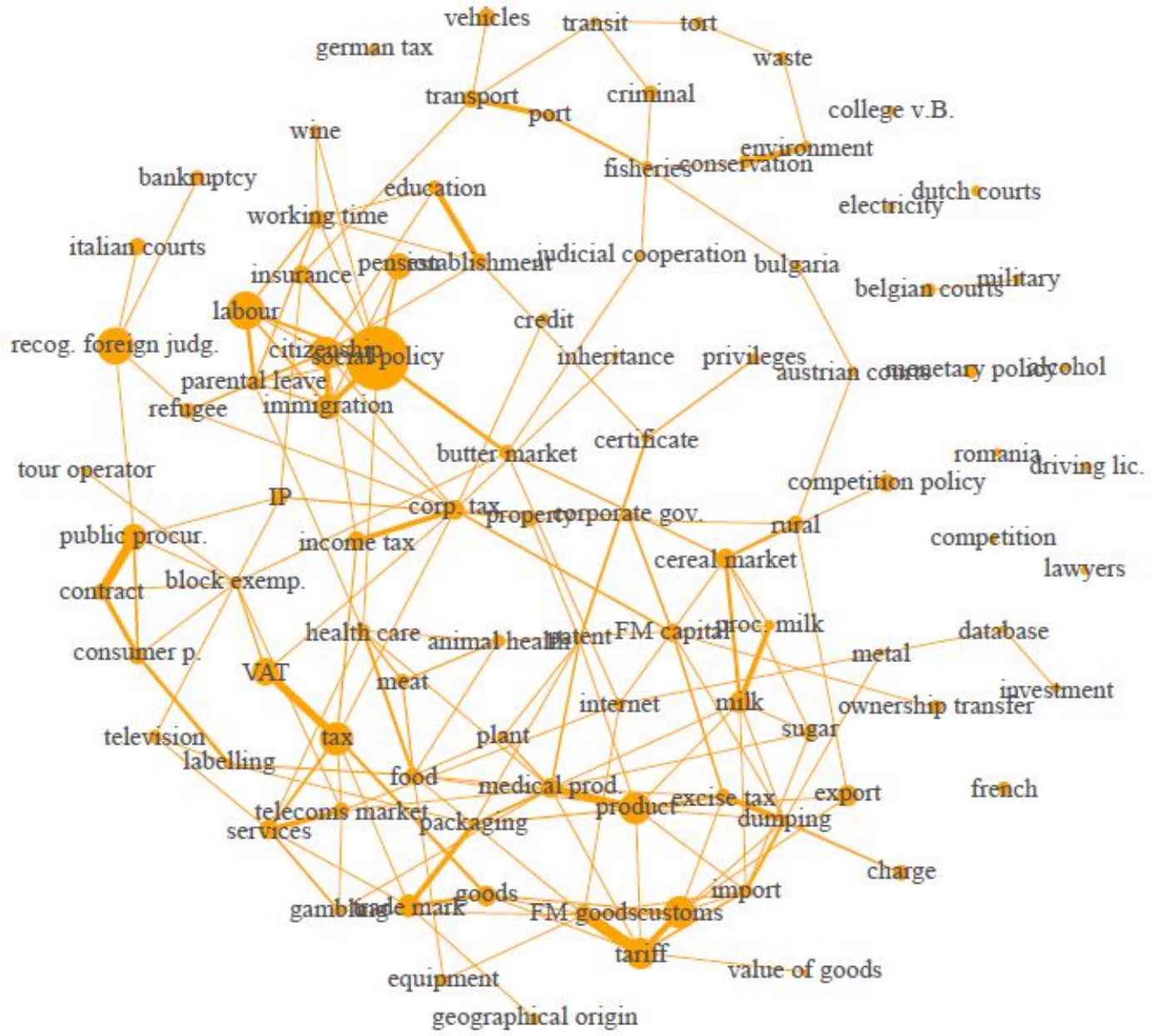

Figure 12: Topic model (LDA) with 97 labelled topics represented as a network.

Note: Number of topics is chosen so as to minimize perplexity. Node size denotes overall topic prevalence across. Edge thickness denotes correlation among topics. 


\section{A.3 Corpus Dissimilarity Analysis}

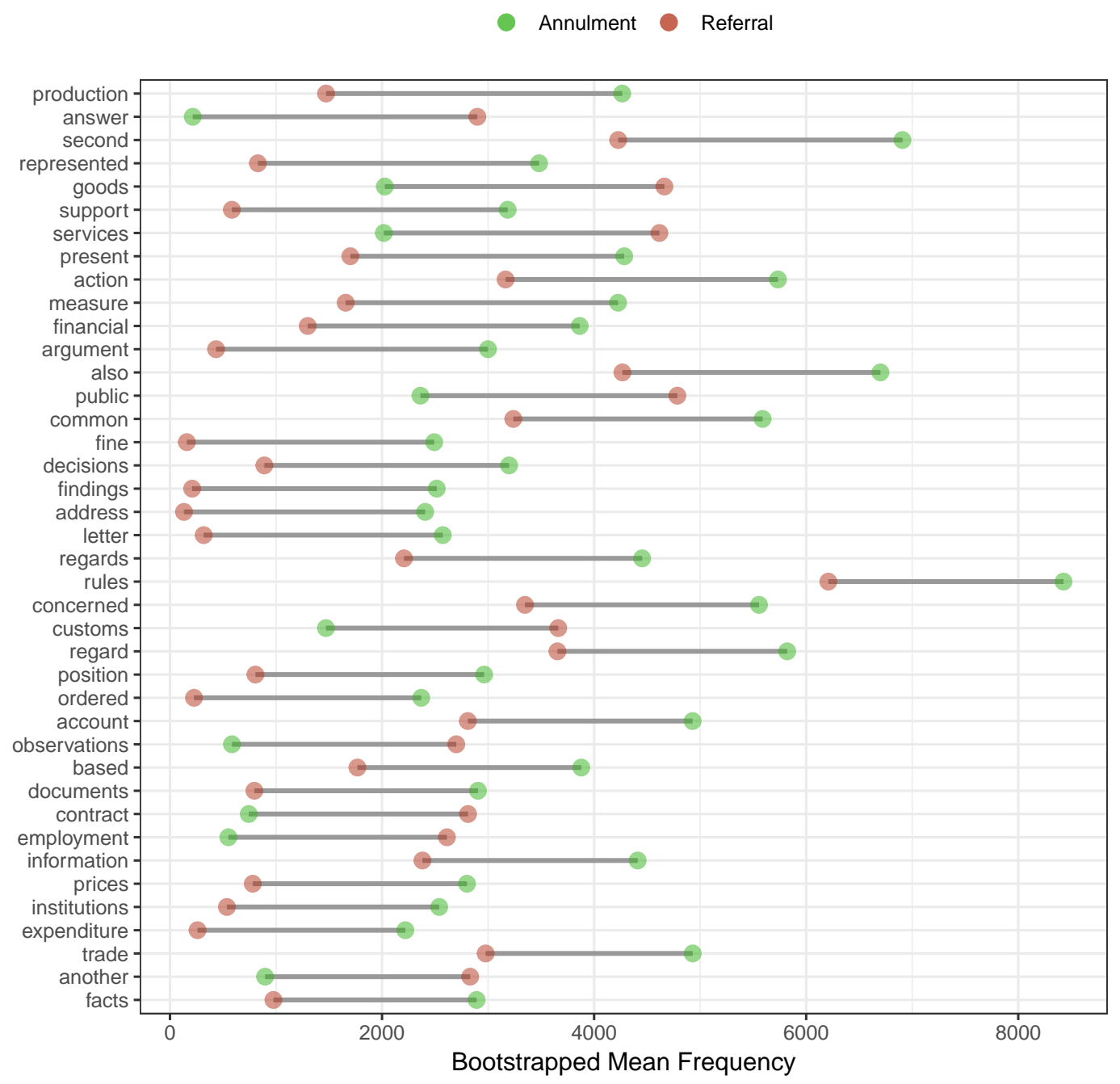

Figure 13: Corpus dissimilarity: Annulment - Referral

Note: The plot displays the most distinctive terms in pairwise comparisons of the procedures. Words are sorted by bootstrapped mean difference. 


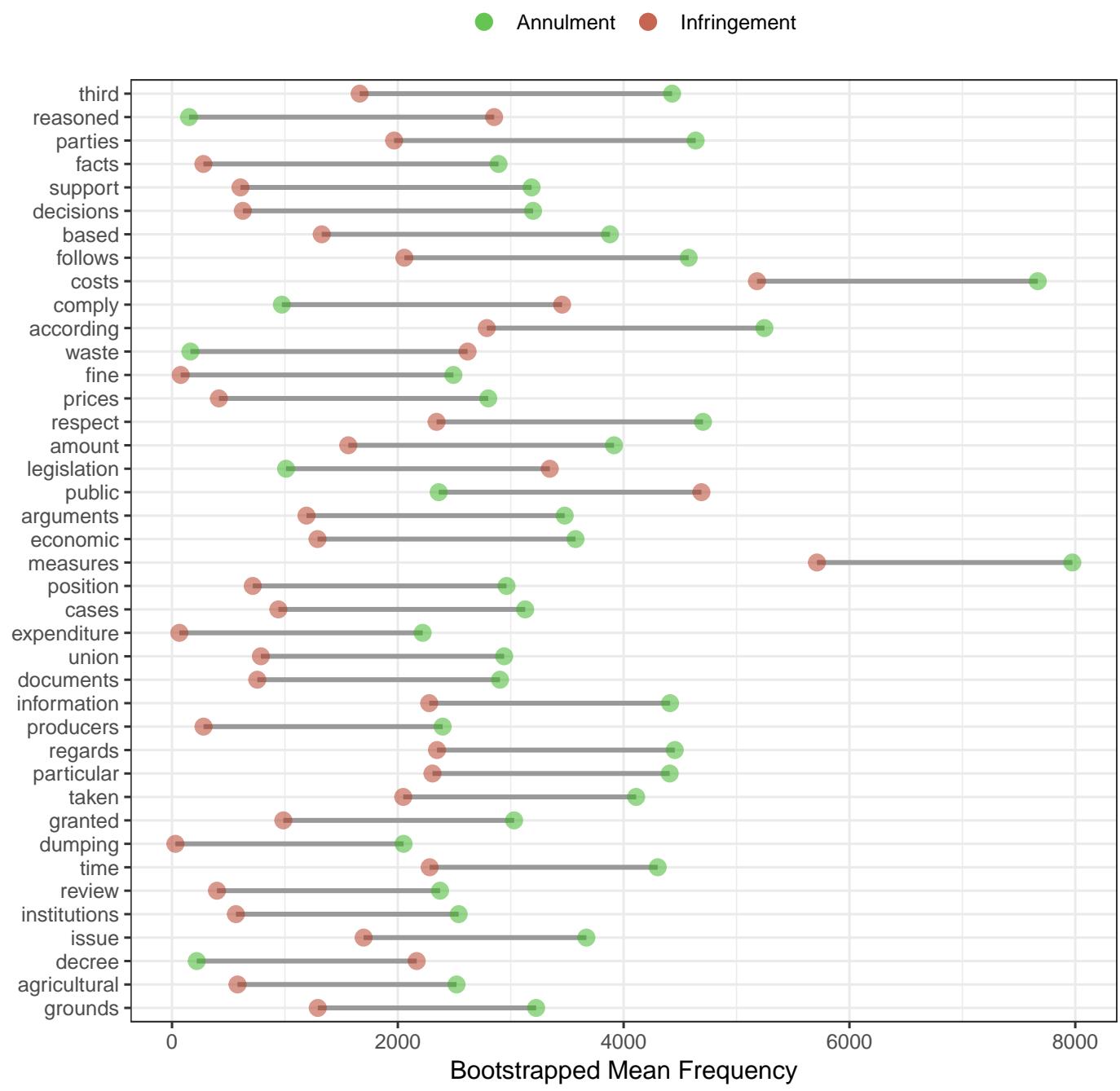

Figure 14: Corpus dissimilarity: Annulment - Infringement

Note: The plot displays the most distinctive terms in pairwise comparisons of the procedures. Words are sorted by bootstrapped mean difference.

\section{A.4 Validation}

The methods applied in the present study rest on simplifying assumptions about the data-generating process. Specifically, they rely on the bag-of-words approach, which means that complex rulings are reduced to vectors of word counts without consideration for syntax and context. In consequence, validation is recommended (Grimmer and Stewart, 2013). To that end, we relate two of our topic models 
to manually collected decisions on family reunion issues. This set of decisions was assembled in the context of a longitudinal study of the ECJ's case law on family reunion (De Somer, 2019). Cases included in the dataset are cases that (1) explicitly refer to EU legislation on family reunion, migrant worker, asylum or citizenship, and (2) involve at least one third-country national. ${ }^{16}$ In total 67 cases, covering four decades, were selected. Of the 67 decisions, 58 are preliminary rulings, eight are infringement and one is an annulment action.

Generally speaking, if we consider only preliminary rulings, family reunion cases should be strongly correlated with topic 16 in our static topic model (Figure 11) and topic 6 (residence \& citizenship) from our dynamic topic model of preliminary rulings (Figure 7). Moreover, we should expect decisions that are more central to the Court's family reunion jurisprudence to exhibit both a higher $\theta_{16}$ (static topic model) and a higher $\theta_{T 6}$ (dynamic topic model). To measure the degree of embeddedness of decisions in the Court's case law, we use cross-citations to construct an indicator of jurisprudential centrality.

\footnotetext{
${ }^{16}$ We refer to De Somer (2019) for detail of the operationalisation of these two criteria.
} 


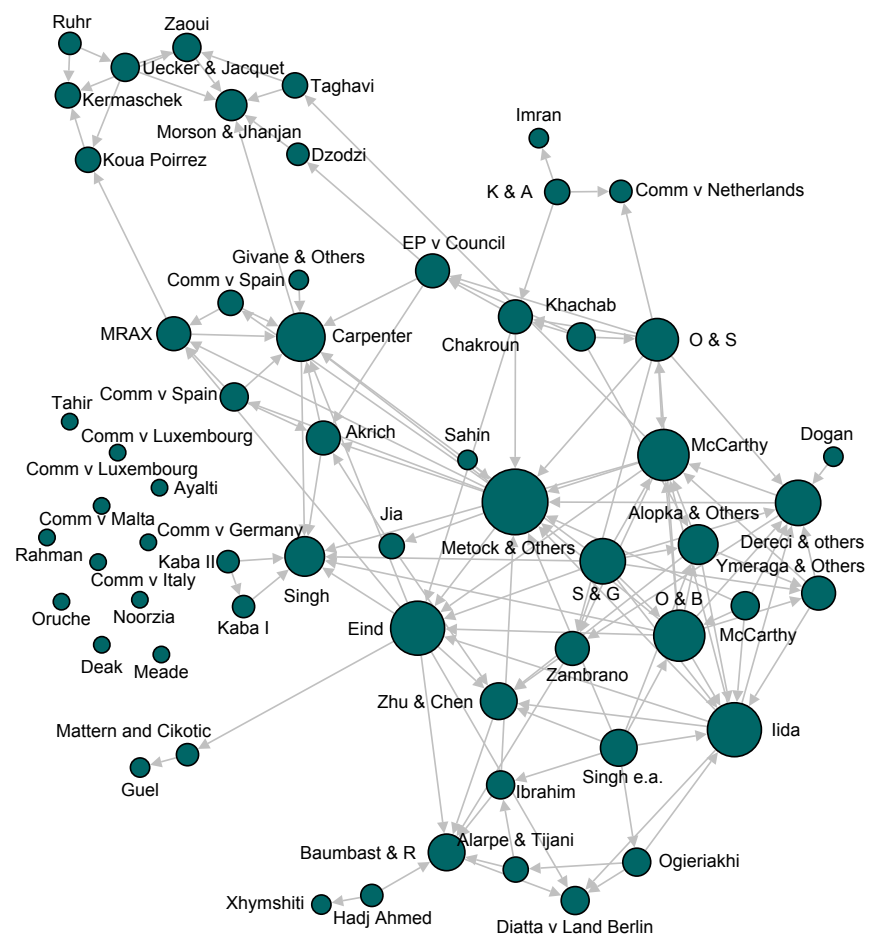

Figure 15: Case citation network of manually collected family reunion cases.

Our indicator is simply the sum of in-degree and out-degree citations. It reflects the intuition that decisions which either cite more decisions or are more cited by other decisions in the citation network (or both) are likely to share more doctrinal language. We hypothesize that more embedded decisions will exhibit a higher $\theta$ for the relevant topic. Figure 15 illustrates the network of case citations with larger nodes denoting greater jurisprudential embeddedness.

As shown in Figure 16, manually collected family reunion cases are strongly related to the expected topics-namely topic 16 (residence) for the static LDA model and topic 6 (residence and citizenship) for the dynamic model. This is strong evidence that the family reunion cases are correctly classified by our topic models. 


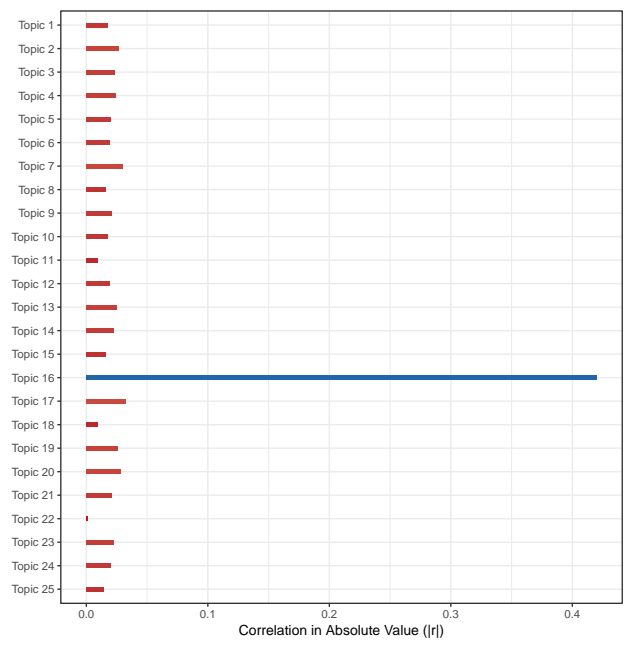

(a) Static

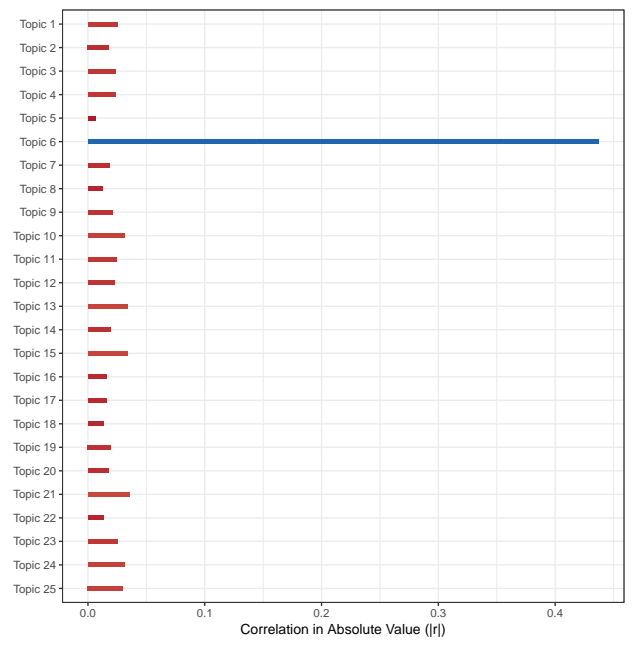

(b) Dynamic

Figure 16: Correlation between manually collected family reunion cases and topics from static (a) and dynamic (b) topic models.

Note: We labelled Topic 16 in Figure 16a as "residence" (see Figure 11 and 2). Topic 6 in Figure 16b is labelled as "residence \& citizenship" (see Figure 7). Only preliminary rulings are considered.

Next, Figure 17 depicts the relationship between $\theta_{16}$ (from LDA model) and our measure of jurisprudential embeddedness. As expected, higher jurisprudential centrality correlates with higher topic proportion. Cases that cite more or get cited more (or both) show a greater proportion of topic 16. Since case citation is driven by law-finding and law creation rather than by fact-finding, this suggests that topic 16 is capturing legal doctrines as well as factual regularities. Interestingly, the fitted loess curve in Figure 17 follows a convex shape. This implies that jurisprudential centrality is associated with $\theta_{16}$ up to a certain level, presumably because the topic also captures factual regularities. 


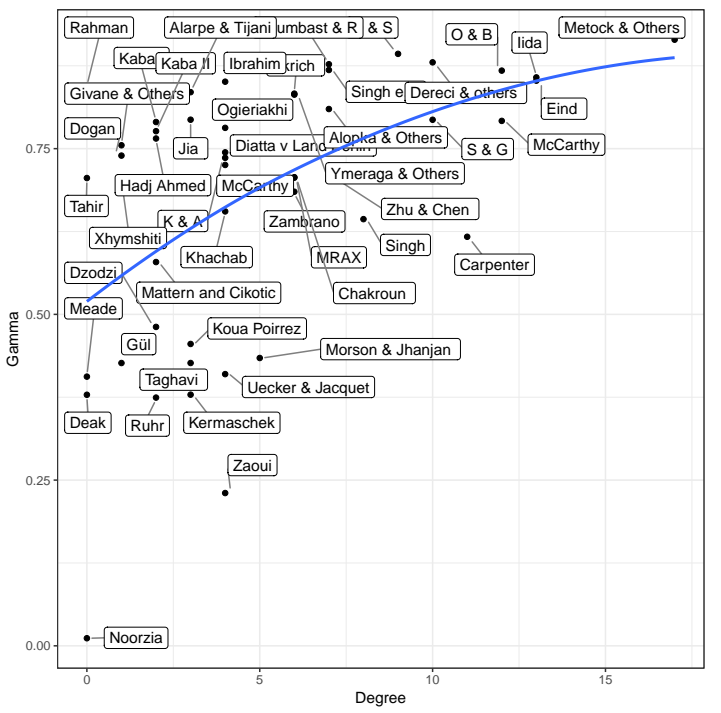

Figure 17: Correlation between $\theta_{16}$ from static LDA model (Figure 11 in Supplementary Materials) and jurisprudential embeddedness of manually collected family reunion cases with loess curve. 